\title{
A Review on Nano-Based Drug Delivery System for Cancer Chemoimmunotherapy
}

Cite as

Nano-Micro Lett.

(2020) 12:142

Received: 26 April 2020

Accepted: 11 June 2020

Published online: 5 July 2020

(C) The Author(s) 2020

\author{
Weiwei Mu${ }^{1}$, Qihui $\mathrm{Chu}^{1}$, Yongjun $\mathrm{Liu}^{1}, \mathrm{Na} \mathrm{Zhang}^{1} \bowtie$ \\ $\triangle$ Na Zhang, zhangnancy9@sdu.edu.cn \\ 1 Department of Pharmaceutics, Key Laboratory of Chemical Biology (Ministry of Education), School \\ of Pharmaceutical Sciences, Cheeloo College of Medicine, Shandong University, 44 Wenhuaxi Road, \\ Jinan 250012, People's Republic of China
}

\section{HIGHLIGHTS}

- The current approaches of cancer immunotherapy were summarized.

- The prospects in combination of chemotherapy and immunotherapy were discussed.

- The recent progress of nano-based drug delivery systems applied for cancer chemoimmunotherapy was further categorized and reviewed.

\begin{abstract}
Although notable progress has been made on novel cancer treatments, the overall survival rate and therapeutic effects are still unsatisfactory for cancer patients. Chemoimmunotherapy, combining chemotherapeutics and immunotherapeutic drugs, has emerged as a promising approach for cancer treatment, with the advantages of cooperating two kinds of treatment mechanism, reducing the dosage of the drug and enhancing therapeutic effect. Moreover, nano-based drug delivery system (NDDS) was applied to encapsulate chemotherapeutic agents and exhibited outstanding properties such as targeted delivery, tumor microenvironment response and site-specific release. Several nanocarriers have been approved in clinical cancer chemotherapy and showed significant improvement in therapeutic efficiency compared with traditional formulations, such as liposomes (Doxil ${ }^{\circledR}$, Lipusu $^{\circledR}$ ), nanoparticles (Abraxane ${ }^{\circledR}$ ) and micelles $\left(\right.$ Genexol-PM $\left.{ }^{\circledR}\right)$.

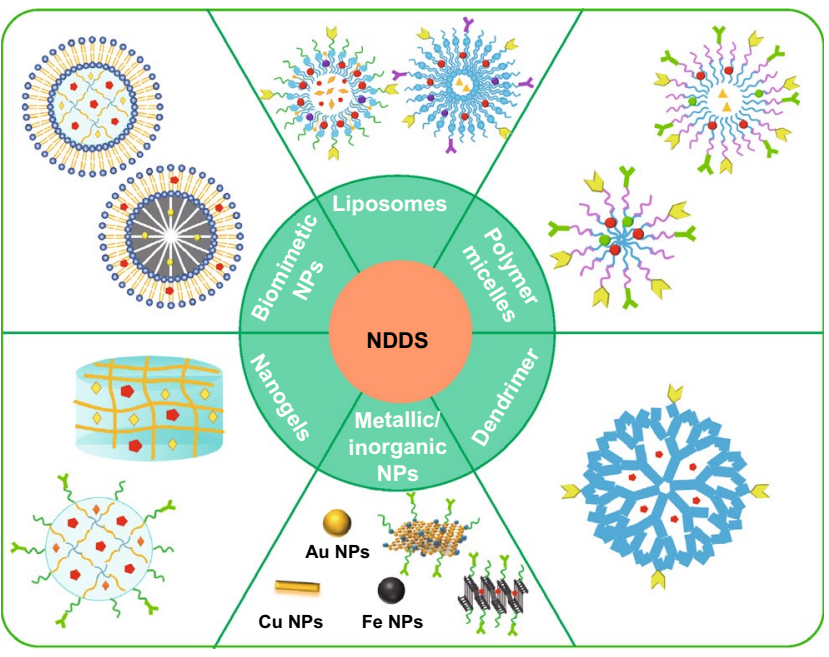
The applications of NDDS to chemoimmunotherapy would be a powerful strategy for future cancer treatment, which could greatly enhance the therapeutic efficacy, reduce the side effects and optimize the clinical outcomes of cancer patients. Herein, the current approaches of cancer immunotherapy and chemoimmunotherapy were discussed, and recent advances of NDDS applied for chemoimmunotherapy were further reviewed.
\end{abstract}

KEYWORDS Cancer therapy; Chemotherapy; Immunotherapy; Chemoimmunotherapy; Nano-based drug delivery system 


\section{Introduction}

Cancer is still the main cause of death for patients worldwide with increasing incidence [1,2], and the research into cancer treatment is under the spotlight. Surgery, radiotherapy, chemotherapy and immunotherapy, as well as those combinational regimens are now the main clinical strategies [3]. Among those, immunotherapy is now considered as the potentially powerful approach to overcome the cancer due to the completely different way for cancer treatment, which acts by modulating the systemic immune system rather than focusing on the tumor itself [4-7]. Since the first immune checkpoints blockade agent ipilimumab approved by the US Food and Drug Administration (FDA) in 2011, cancer immunotherapy has come of age and shown great clinical success [8]. Till now, additional six immune checkpoints blockade agents $\left(\right.$ Keytruda $^{\circledR}$, Opdivo $^{\circledR}$ Tecentriq $^{\circledR}$, Imfinzi $^{\circledR}$, Bavencio $^{\circledR}$ and Libtayo ${ }^{\circledR}$ ) have been approved by FDA, and many other forceful immunotherapy drugs have been in clinical trials [9-12]. Nevertheless, immunotherapy has met great challenges in some tumor types or patients in clinical $[13,14]$, including drug resistance of immune checkpoints inhibitors, weak immunogenicity of therapeutic vaccines, significant immune-related adverse events (iRAE), off-target side effects [15] and so on.

Chemotherapy is the vital weapon of cancer therapy [16]. Chemotherapy drugs have long been considered to induce immune suppressive; however, massive preclinical studies proved that chemotherapy could offer additional benefits to immunotherapy, even some cytotoxic drugs could trigger antitumor immunity [17], such as cyclin-dependent kinases 4 and 6 inhibitor $[18,19]$. Chemoimmunotherapy, the combination of chemotherapy and immunotherapy, provides a superior synergistic effect for enhancing antitumor efficiency. Firstly, chemotherapy drugs kill tumor cells directly, while immunotherapy reactivates immune response to kill cancer cells. Besides, the effective time was complementary, for which chemotherapy drugs have quick action but short action time, while immunotherapy could produce a strong and long-lasting antitumor effect. Additionally, immunotherapy could overcome the deficiencies on chemotherapy such as killing chemotherapeutical-resistant cells and cancer stem cells $[13,16]$. Current data suggested that chemoimmunotherapy would bring incomparable prospects for optimizing the clinical prognosis of patients [20]. For example, the combination of carboplatin or cisplatin, pemetrexed with pembrolizumab, has been approved by FDA for the first-line treatment of non-small cell lung cancer (NSCLC).

To ensure optimal synergistic antitumor efficacy, some issues should be concerned, including distinct pharmacokinetics and in vivo distribution of both agents, insufficient tumor specificity and tumor accumulation, unascertainable drug ratios at tumor tissues and serious systemic side effects $[21,22]$. Nano-based drug delivery system (NDDS) could improve the in vivo pharmacokinetics behaviors, increase the stability of drugs, realize the targeted delivery and controlled release of drugs, thus holding great promise for chemoimmunotherapy [23]. Moreover, recent studies demonstrated that nanoparticles (NPs) could re-model immunosuppressive tumor microenvironment (TME) [24]. Therefore, NDDS applied to chemoimmunotherapy is nowadays the hotspot in cancer treatment. Herein, the current approaches of cancer immunotherapy as well as chemoimmunotherapy were discussed. Next, the current applications of NDDS in chemoimmunotherapy were summarized.

\section{Cancer Immunotherapy}

Cancer immunotherapy has rapidly developed as a promising strategy for cancer treatment. Cancer immunity consists of several key steps, which is so-called cancer-immunity cycle, including release of cancer cell antigens, cancer antigens presentation by antigen-presenting cells (APCs), priming and activation of $\mathrm{T}$ cells, trafficking and infiltration of $\mathrm{T}$ cells to tumors and finally the recognition and killing of tumor cells by cytotoxic T cells (Fig. 1) [25]. It is theoretically

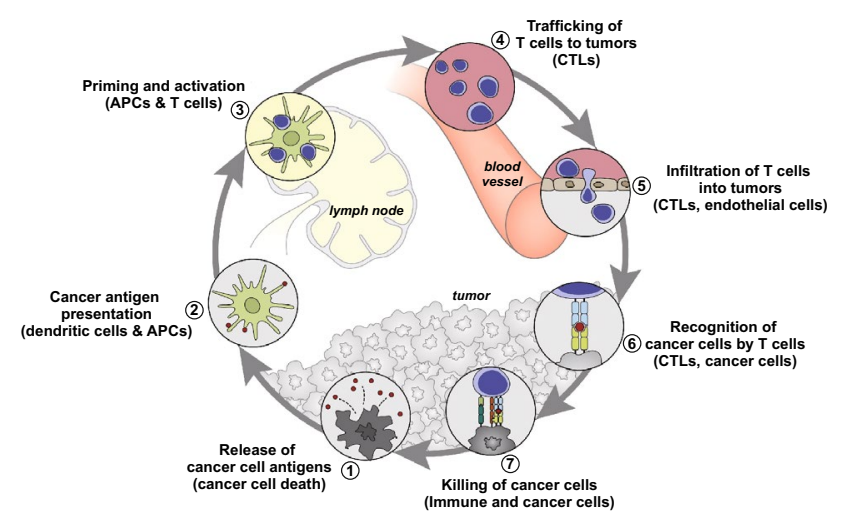

Fig. 1 Scheme illustration of the cancer-immunity cycle. Reproduced with permission from Ref. [25]. Copyright 2013 Elsevier 
possible that each step among them might be the potential therapeutic target with various methods. Aiming to these targets, current approaches to cancer immunotherapy mainly include therapeutic antibodies, cancer vaccines, adoptive cell therapy and cytokine therapy [26].

\subsection{Therapeutic Antibodies}

At present, dozens of therapeutic antibodies, such as brentuximab vedotin (Adcetris ${ }^{\circledR}$ ) and ibritumomab tiuxetan $\left(\right.$ Zevalin $\left.^{\circledR}\right)$ [27], have been approved by FDA for the treatment of various cancers, and some other therapeutic monoclonal antibodies (mAbs) were in clinical trials [28]. The therapeutic antibodies approved by FDA and the National Medical Products Administration (NMPA) for cancer immunotherapy are summarized in Table 1.

Notably, immune checkpoint therapy has brought significant clinical advances against cancer [29]. Immune checkpoints are vital for maintaining self-tolerance, regulating the duration and magnitude of immune response for immune system. By blocking immune checkpoints, immune checkpoint therapy can reactivate immune cells and enhance the killing ability of immune cells to cancer cells. Up to now, seven immune checkpoint agents have been approved by FDA, which are expected to be approved for various cancers in the future [30]. Ipilimumab $\left(\right.$ Yervoy $^{\circledR}$ ) is the first immune checkpoint agent, approved for the treatment of melanoma, which acts by blocking the cytotoxic T-lymphocyte-associated protein 4 (CTLA-4) and re-activating T cells. In stage IV melanoma patients, the mortality was reduced to $34 \%$ after treatment with ipilimumab plus dacarbazine, compared with dacarbazine plus placebo [31]. Besides, programmed death 1 (PD-1)/programmed death ligand 1 (PD-L1) antibody is another main category in immunotherapy, which could reactivate $\mathrm{T}$ cells by blocking the binding of PD-1 to PD-L1 and thus kill tumor cell indirectly. Nivolumab $\left(\right.$ Opdivo $\left.^{\circledR}\right)$, pembrolizumab (Keytruda ${ }^{\circledR}$ ) and cemiplimab (Libtayo ${ }^{\circledR}$ ) are PD-1 antibodies for the treatment of advanced melanoma [32], metastatic cutaneous squamous cell carcinoma (CSCC) [33], respectively. While on the other hand, atezolizumab (Tecentriq $\left.{ }^{\circledR}\right)$, avelumab (Bavencio ${ }^{\circledR}$ ) and durvalumab (Imfinzi ${ }^{\circledR}$ ) are the PD-L1 blocking agents approved for the treatment of advanced or metastatic urothelial carcinoma, Merkel cell carcinoma (mMCC) [34] and urothelial carcinoma [35], respectively. Additionally, there are also other immune checkpoints as the potential targets in immune checkpoint therapy, such as $\mathrm{T}$ cell immunoglobulin and mucin-domain containing-3 (TIM-3), indoleamine-pyrrole 2,3-dioxygenase-1

Table 1 Summary of therapeutic antibodies approved for cancer immunotherapy

\begin{tabular}{|c|c|c|c|c|}
\hline Mechanism & Target & Drug & Type of cancer & $\begin{array}{l}\text { Time to } \\
\text { approved }\end{array}$ \\
\hline \multirow{11}{*}{$\begin{array}{l}\text { Blockade of } \\
\text { immune } \\
\text { checkpoints }\end{array}$} & CTLA-4 & Ipilimumab & Unresectable or metastatic melanoma & 2011 \\
\hline & PD-1 & Nivolumab & $\begin{array}{l}\text { Classic Hodgkin's lymphoma, Melanoma, non-small cell lung cancer and renal cell } \\
\text { carcinoma }\end{array}$ & 2014 \\
\hline & PD-1 & Pembrolizumab & $\begin{array}{l}\text { Advanced, unresectable or metastatic melanoma; non-small cell lung cancer and head } \\
\text { and neck cancer }\end{array}$ & 2014 \\
\hline & PD-1 & Cemiplimab & $\begin{array}{l}\text { Metastatic cutaneous squamous cell carcinoma or locally advanced cutaneous squa- } \\
\text { mous cell carcinoma }\end{array}$ & 2018 \\
\hline & PD-1 & Toripalimab & Unresectable or metastatic melanoma & 2018 \\
\hline & PD-1 & Sintilimab & $\begin{array}{l}\text { Classical Hodgkin's lymphoma in patients who have relapsed or are refractory } \\
\text { after } \geq 2 \text { lines of systemic chemotherapy }\end{array}$ & 2018 \\
\hline & PD-1 & Camrelizumab & $\begin{array}{l}\text { Relapsed or refractory classic Hodgkin's lymphoma treated with at least second-line } \\
\text { chemotherapy }\end{array}$ & 2019 \\
\hline & PD-1 & Tislelizumab & $\begin{array}{l}\text { Relapsed or refractory classical Hodgkin's lymphoma after at least second-line chemo- } \\
\text { therapy }\end{array}$ & 2019 \\
\hline & PD-L1 & Atezolizumab & Locally advanced or metastatic urothelial carcinoma & 2016 \\
\hline & PD-L1 & Durvalumab & Locally advanced or metastatic urothelial carcinoma & 2017 \\
\hline & PD-L1 & Avelumab & Metastatic Merkel cell carcinoma (mMCC) & 2017 \\
\hline
\end{tabular}


(IDO-1) and lymphocyte-activation gene 3 (LAG-3), and their related antibodies are being evaluated in preclinical tumor models and/or in the clinic. At present, 4 immune checkpoint antibodies (toripalimab, sintilimab, camrelizumab and tislelizumab) developed in China have been approved by NMPA for cancer immunotherapy.

Recently, the combination of two immune checkpoints in tumor therapy showed a good prospect. For instance, the combination of PD-1 and CTLA-4 antibody has been used for melanoma immunotherapy. The response rate was $61 \%$, and over $22 \%$ patients showing a complete response [36].

\subsection{Cancer Vaccines}

The use of vaccines in prevention and treatment of cancers has been explored for more than a century. A remarkable progress has been achieved in the development of preventive vaccines-hepatitis B and human papilloma viruses (HPVs). HPVs vaccines have demonstrated definite potentials to prevent the cancers and saved millions of lives [37]. However, the development of therapeutic vaccines was painfully slow and faced numerous challenges. Nowadays, Sipuleucel-T (Provenge ${ }^{\circledR}$ ) was the only therapeutic cancer vaccine approved by FDA, which is applied for the treatment of prostate cancer. Depending on the uptake of dendritic cells (DCs) and antigen presentation, cancer vaccines need to induce antigen-specific $\mathrm{CD}^{+}$cytolytic $\mathrm{T}$ cells (CTLs) and antigen-specific $\mathrm{CD} 4^{+} \mathrm{T}$ cells for optimally efficacy [38].

With the deep understanding of tumor immunology and the success of Sipuleucel-T, several types of cancer vaccines and other diverse vaccines have now been evaluated in phase II and phase III clinical trials [39, 40], such as granulocyte-macrophage colony-stimulating factor (GMCSF) gene-modified autologous tumor vaccine (CG8123), peptide-based glycoprotein 100 (Gp100), TGF- $\beta 2$ antisense/GM-CSF gene-modified autologous tumor cell vaccine (TAG) and New York esophageal carcinoma antigen 1 Plasmid DNA (pPJV7611) [41-43]. Cancer vaccines often combined with adjuvants to produce powerful immune responses [44]. The commonly used adjuvants mainly include cytokines/endogenous immunomodulators (e.g., GM-CSF), microbes and microbial derivatives (e.g., cytosine-phosphate diesterguaninen $(\mathrm{CpG})$, poly $\mathrm{I}: \mathrm{C})$, mineral salts (e.g., alum), viral vectors (e.g., adenovirus, vaccinia), oil emulsions or surfactants (e.g., Montanide ${ }^{\mathrm{TM}}$ ) and so on [38, 45-48].

\subsection{Adoptive Cell Therapy}

Adoptive cell therapy (ACT) relies on the ex vivo generation of highly active and tumor-specific lymphocytes, and then a large number of these lymphocytes were injected to the autologous hosts for cancer treatment [49]. These lymphocytes mainly include lymphokine-activated killer cells (LAK cells), chimeric antigen receptor T cells (CAR-T cells), tumor-infiltrating lymphocytes (TIL), natural killer (NK), DCs, macrophages and so on.

ACT has multiple advantages compared with other cancer immunotherapeutic approaches. Large numbers of antitumor lymphocytes can be readily grown in vitro and recognize the tumor specifically, then play effective antitumor immune effect [50]. For example, anti-CD19 CAR-T cells showed high antitumor efficacy in patients with relapsed B-cell acute lymphoblastic leukemia (B-ALL) and B-cell non-Hodgkin lymphoma, and the complete response rate was $70-94 \%$ in various trials [51]. Two kinds of ACT with anti-CD19-modified $\mathrm{T}$ cells have been approved by FDA, i.e., Kymriah ${ }^{\mathrm{TM}}$ and Yescarta ${ }^{\circledR}$ [52], which marked an era arriving of ACT. Suitable NDDS have been applied for adoptive cell therapy. For example, Mitragotr et al. [53] developed an engineered particle (name as "backpack"), which could robustly bind on the surfaces of macrophages and regulate the phenotypes of macrophages by sustained releasing cytokines in vivo. The backpack-loaded macrophages could keep antitumor phenotypes for up to 5 days and showed superior antitumor effect compared with free cytokine-treated macrophages.

\subsection{Cytokines}

Cytokines with biological activity could enhance the immune response of patients via inducing direct apoptosis effects and generate the antitumor effects indirectly [54, 55]. Different cytokines have been intensively applied in clinical cancer treatment, such as interferons (INFs), interleukins (ILs), tumor necrosis factors (TNFs) and granulocyte-macrophage colony-stimulating factor (GM-CSF) [56].

IFN- $\alpha$ was the first cytokine approved into market in 1995 and used for leukemia and advanced melanoma. IFN- $\gamma$ has 
properties of immunomodulation, which could induce the expression of MHC-I/II by APC, activate NK/macrophages and induce the differentiation of $\mathrm{T}$ cells $[55,57]$. IL-2, a multifunctional cytokine, is essential in differentiation and proliferation of $\mathrm{T}$ cells, NK, macrophages and B cells, which is effective in metastatic melanoma and renal carcinoma [58]. Other lymphokines are also being evaluated, such as IL-7, IL-12 and IL-15 [57]. TNFs are one kind of most active biological factors found to kill tumor directly $[59,60]$. GM-CSF showed potential to promote the growth and differentiation of macrophages/granulocytes/DCs, which could enhance antigen presentation [61].

Although revealing obvious advantages, immunotherapy has met great challenges in some tumor types or patients in clinics, including drug resistance of immune checkpoints inhibitors, weak immunogenicity of therapeutic vaccines, significant immune-related adverse events (iRAE) and offtarget side effects etc. [62].

\section{Cancer Chemoimmunotherapy}

\subsection{Cancer Chemotherapy}

Caner chemoimmunotherapy is a promising approach for improving antitumor efficiency and has been widely studied in preclinical and clinical research. Chemotherapy is one of the most used cancer treatments, which offers the best hope of cancer. Chemotherapy takes effect by toxic compounds that inhibit the fast proliferation of cancer cells [63]. Unfortunately, other rapid growth cells may be inhibited by chemotherapeutic drugs as well, such as hair follicles cells, bone marrow cells and gastrointestinal tract cells. Thus, toxic side effects of chemotherapy usually include hair loss, severe nausea and bowel problems, etc. Chemotherapy frequently fails in cancer treatments due to poor pharmacokinetics and wide distribution in vivo, insufficient delivery and multiple drug resistance (MDR) [64]. At present, combination therapy was used to enhance the curative effect of chemotherapy, such as chemotherapy combined chemotherapy, surgical treatment, radiotherapy, photothermal therapy [65], photodynamic therapy [66], immunotherapy [67] and so on. Among these, the combination of chemotherapy and immunotherapy (chemoimmunotherapy) provides a superior synergistic effect for enhancing antitumor efficiency.

\subsection{How Chemotherapy Influence Cancer Immunotherapy?}

Chemotherapy drug might induce immunomodulation mainly by enhancing intrinsic tumor cell immunogenicity [68], regulating the suppressive influence of $T$ cells [69] and impacting the function of other cells, such as myeloidderived suppressor cells (MDSCs) [70] and DCs [71]. Studies have shown that chemotherapeutics could enhance intrinsic immunogenicity of tumor cells by upregulating the expression of tumor antigens [72] and MHC-I [73], inducing the expression of costimulatory molecules [74], downregulating the immune checkpoint molecules expressed on the tumor cell surface [75], inducing tumor cell death by secreting ATP or expressing calreticulin [68] and so on [76, 77].

Chemotherapeutic agents in appropriate doses can regulate the suppressive influence of tumor-associated $\mathrm{T}$ cells. Regulatory $\mathrm{T}$ cells (Tregs) are immunosuppressive CD4+ T cells and usually downregulate the proliferation of effector $\mathrm{T}$ cells. The numbers of Tregs account for only about $4 \%$ of total CD4+ T cells, while up to 20-30\% of total CD4+ T cells in TME, that would suppress the antitumor immune remarkably [78-80]. Studies have demonstrated that some chemotherapeutic agents can regulate the suppression of Tregs to a certain extent [81]. For example, selective CDK4/6 inhibitors (such as abemaciclib) could promote antitumor immunity by two aspects [19]. On the one hand, CDK4/6 inhibitors stimulate the production of IFN-III and enhance tumor antigen presentation. On the other hand, CDK4/6 inhibitors could suppress the proliferation of Tregs. In a study by combining abemaciclib with PD-L1 inhibitor for the treatment of MMTV-rtTA/tetO-HER2 tumors in mice, the tumor volumes reduced $70 \%$ by day 13 .

With the advantages of chemoimmunotherapy, numerous clinical trials have shown delightful results in cancer treatment (Table 2). Chemoimmunotherapy exhibited remarkable clinical outcomes of cancer patients. For example, E. Ellebaek et al. analyzed metastatic melanoma patient's treatment with DC vaccination plus cyclophosphamide/ celecoxib/IL-2. Compared with treatment without cyclophosphamide and celecoxib, the 6-month survival increased significantly [82]. Nowak et al. had explored the immunological effect of CD40-activating antibody with cisplatin/pemetrexed in malignant pleural mesothelioma, in which more patients showed transient tumor-specific $\mathrm{T}$ cell responses and achieved long-term survival [83]. The combination of 
Table 2 Summary of clinical trials for cancer chemoimmunotherapy

\begin{tabular}{|c|c|c|c|c|}
\hline Clinical trial & Immunotherapy drug & Chemotherapy drug & Type of cancer & References \\
\hline Phase $1 b$ & CD40-activating antibody CP-870,893 & Cisplatin and pemetrexed & Malignant pleural mesothelioma & {$[83]$} \\
\hline Phase 2 & Ipilimumab & Paclitaxel and carboplatin & Non-small cell lung cancer & [76] \\
\hline Phase 2 & $\begin{array}{l}\text { Cox-2 inhibitor, granulocyte colony-stimulating } \\
\text { factor, a sulfhydryl (SH) donor and a hemod- } \\
\text { erivative }\end{array}$ & Cyclophosphamide & $\begin{array}{l}\text { Pancreatic adenocarcinomas, non- } \\
\text { small cell lung cancer or prostate } \\
\text { cancer }\end{array}$ & {$[161]$} \\
\hline Phase 2 & Bevacizumab & Cyclophosphamide & Advanced ovarian cancer patients & {$[84]$} \\
\hline Phase 2 & Oncolytic adenovirus & Cyclophosphamide & Advanced soild tumors & {$[81]$} \\
\hline Phase 2 & Oncolytic adenovirus & Temozolomide & Advanced soild tumors & {$[162]$} \\
\hline Phase 2 & Interleukin-2 & Cyclophosphamide & Metastatic melanoma & [82] \\
\hline Phase 3 & GM-CSF + telomerase peptide vaccine GV1001 & Gemcitabine/capecitabine & Advanced pancreatic cancer & [87] \\
\hline
\end{tabular}

carboplatin or cisplatin, pemetrexed/pembrolizumab, was approved by FDA for the first-line treatment of NSCLC.

As shown in recent clinical trials (Table 2), the addition of chemotherapeutic drugs to immunotherapy could synergistically increase the antitumor effects compared with either therapy alone [84, 85]. Nevertheless, some clinical trials of antitumor effect are still not ideal, such as inadequate $\mathrm{T}$ cells response, great differentiation in curative effect among tumor patients, and many patients do not have a good response [86]. Middleton et al. conducted a phase 3 clinic trial of telomerase peptide vaccine (GV1001) plus chemotherapy drug in pancreatic cancer to assess the efficacy and safety. Results interpreted that GV1001 vaccine plus chemotherapy didn't improve overall survival [87]. It was suggested that new approaches to further enhance the immune response effects during chemoimmunotherapy are explored.

\section{Nanocarriers for Cancer Chemoimmunotherapy}

NDDS provides promising strategies for cancer chemoimmunotherapy, because they are easy to be internalized by immune cells and could re-educate TME due to special physical and chemical properties, thus boost the immune system [88]. NDDS can increase solubility and bioavailability of the agents, prolong the circulation time of agents via passive or active targeting, increase the accumulation of therapeutic agents in tumor tissue as well as improve the pharmacokinetics behaviors in vivo, leading to enhanced therapeutic effects and reduced side effects [89-92].
Concerning NDDS applied to chemoimmunotherapy, there are several flexible approaches to realize the codelivery of multiple agents [93, 94]. For the combination of multiple agents in chemoimmunotherapy, one agent can be administered as free form and others by NDDS (Free drug + Nano), or both were delivered by similar or different NDDS, respectively (Nano + Nano), or both agents were coencapsulated in one NDDS (co-encapsulation). The advantages and disadvantages of the three approaches to deliver multiple agents in chemoimmunotherapy are summarized in Table 3.

The "Free drug + Nano" approach is the closest to the current treatment of cancer with nanomedicines. The "Free drug + Nano" approach exhibited advantages of adjustable prescription, controllable administration interval, easy for preparation, easy industrial scale-up and clinical transformation [95], which mainly include two strategies. One is that immunotherapeutic agent can be delivered in appropriate NPs, and the chemotherapy drug was administered in free form. Yong Taik Lim et al. have designed two poly(lactic-co-glycolic acid) (PLGA) NPs combined with chemotherapy drug paclitaxel (PTX), one is CpG-loaded PLGA NPs (PCNs) to activate BMDCs, the other is IL-10 small interfering RNA-loaded PLGA NPs (PINs) to silence IL-10 [96]. The treatment of PTX followed by PCNs and PINs could enhance antitumor effect and increase survival rate in B16-F10-bearing melanoma mice compare to PTX alone $(p<0.05)$. Another "Free drug + Nano" approach was that immunotherapy agent was administrated in free form, and the chemotherapy drug was loaded in NDDS [97]. Li et al. have reported TME-activatable prodrug vesicle for coloading oxaliplatin (OXA) prodrug and photosensitizer (PS), 
Table 3 Advantages and disadvantages of the three approaches in chemoimmunotherapy

\begin{tabular}{lll}
\hline Approach & Advantages & Disadvantages \\
\hline "Free drug + nano" approach & 1. Adjustable prescription & 1. Undesired distribution of two agents in vivo \\
& 2. Adjustable administration interval & 2. Uncontrolled onset time \\
& 3. Easy for preparation & 3. Insufficient tumor selectivity \\
4. Easy for industrial scale-up & 4. Potential systemic toxicity \\
"Nano + nano" approach & 1. Flexibility in formulation & 1. Mismatched half-lives and in vivo pharmacokinetics \\
& 2. Adjustable administration dosing & 2. Uncontrollable onset time in tumor tissue \\
3. Coordinated distribution of two agents in vivo & \\
& 1. Uniform distribution of the drugs in vivo & 1. Complex preparation process \\
& 2. Accumulation in the tumor tissue at proper ratio & 2. Difficulty in delivering to different targets \\
& 3. Drug release in a controlled manner & \\
& 4. Controlled temporal and spatial delivery of mul- & \\
& tiple agents & \\
\hline
\end{tabular}

which would produce immunogenic cell death (ICD) of the tumor cells [98]. The prodrug vesicle was combined with $\alpha C D 47-m e d i a t e d ~ C D 47$ blockade for antitumor immunity of ICD. The results showed that prodrug vesicle-mediated ICD and CD47 blockade could inhibit tumor growth, suppress metastasis and recurrence of tumor.

The "Nano + Nano" approach might be flexible in formulation, adjustable in administration dosage and have coordinated distribution of two agents $[99,100]$. Our group had developed two twin-like NPs (TCN) for different cells targeting delivery of sorafenib (SF) and IMD-0354 to enhance tumor-localized chemoimmunotherapy [99]. The two TCN exhibited coordinated distribution in vivo and could realize the targeting delivery into different cells, thus ensuring superior synergistic antitumor efficacy and M2-type macrophages polarization ability. Lin et al. developed twotype CD44-targeted liposomes, one for anti-IL6R antibody encapsulating for immunotherapy and the other for DOX encapsulating for chemotherapy to inhibit the metastasis of breast cancer [101]. The NPs- $\alpha$ IL6R Ab-CD44 specifically modified the immune environment in primary tumor by inhibiting the infiltration of TAMs to form a tumor microenvironment unfavorable for metastasis and achieved a significant effect to inhibit the metastasis of breast cancer. For another example, $\mathrm{Li}$ et al. designed low molecular weight heparin (LMWH)-D- $\alpha$-tocopherylsuccinate (TOS) micelles (LT) encapsulating chemotherapeutic drug DOX (LT-DOX) or Toll-like receptor 7 agonist imiquimod (LT-IMQ) with PD-L1 immune checkpoint blockade for chemoimmunotherapy for the treatment of metastatic breast cancer [102]. The two micelles could prolong the circulation time and increase the accumulation in tumor. LT-DOX could initiate a tumor-specific immune response by eliciting ICD, which further strengthened by adjuvant LT-IMQ. The combination with clinically approved PD-L1 checkpoint blockade inhibited the activities of Treg cells, which alleviated the immune inhibition signal and promoted antitumor efficacy.

The "Free drug + Nano" and "Nano + Nano" approaches still suffered from potential mismatched in vivo pharmacokinetics and uncontrolled onset time in tumor tissue. The "co-encapsulation" approach could uniform the distribution of drugs in vivo, control the accumulation in tumor tissue at proper ratio, ensure the drug release in a controlled manner and controlled temporal and spatial delivery of multiple agents [103]. Abundant NDDS have been designed for "coencapsulation" approach in chemoimmunotherapy, including liposomes, polymer micelles, dendrimers, metallic and inorganic NPs, nanogel and biomimetic NPs (Fig. 2). Moreover, the representative NDDS application to chemoimmunotherapy is summarized in Table 4.

\subsection{Liposomes}

Liposomes are the bilayer vesicles composed of phospholipids and cholesterol, which possess advantage of high encapsulation efficiency, targeting ability and low toxicity, holding great prospects in industrial production. The immunotherapy agents, like antigens and adjuvants, can be encapsulated in the hydrophobic core or adsorbed on the lipid surface via charge interactions between agents and lipid or with a chemical linker to the lipid bilayer [119]. Meanwhile, hydrophilic small-molecule chemotherapeutic agents can be encapsulated in the interior aqueous cores, in which hydrophobic agents can be encapsulated into lipid bilayers [104]. 


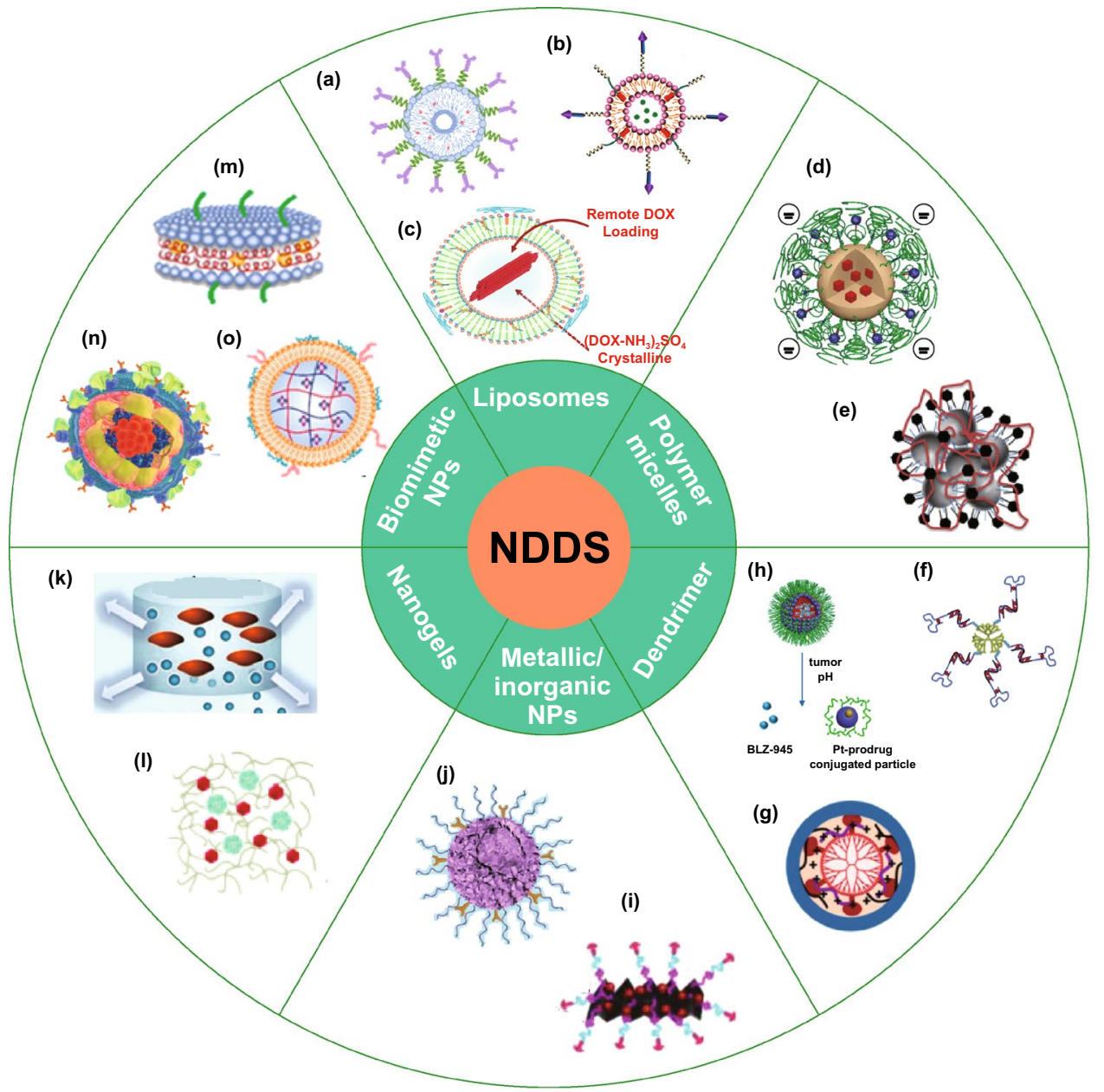

Fig. 2 Summary of NDDS for "co-encapsulation" approach in chemoimmunotherapy. Liposomes, reproduced with permission from Ref. a [104], Copyright 2018 Springer; b [105], Copyright 2019 American Chemical Society; c [106], Copyright 2018 American Chemical Society. Polymer micelles, reproduced with permission from ref d [107], Copyright 2020 John Wiley and Sons; e [108], Copyright 2015 John Wiley and Sons. Dendrimer, reproduced with permission from Ref. f [109], Copyright 2011 Elsevier; g [110], Copyright 2019 lvyspring International Publisher; h [111], Copyright 2017 American Chemical Society. Inorganic NPs and Metallic NPS, reproduced with permission from Ref. i [112], Copyright 2017 American Chemical Society; j [113], Copyright 2019 John Wiley and Sons. Nanogels, reproduced with permission from Ref. k [114], Copyright 2017 Elsevier; l [115], Copyright 2020 Elsevier. Biomimetic NPs, reproduced with permission from Ref. m [116], Copyright 2019 American Chemical Society; n [117], Copyright 2019 American Chemical Society; o [118], Copyright 2017 American Chemical Society

Liposomes have been well applied in cancer therapy with kinds of liposomal products approved. Meanwhile, liposomes were also widely studied as the vehicles to exert the maximal efficacy of chemoimmunotherapy. Chen et al. developed $\mathrm{pH}$ and matrix metalloproteinases (MMPs) dual responsive liposomes (LPDp) with PD-L1 inhibitor conjugate combined with low-dose chemotherapy doxorubicin (DOX) to achieve enhanced antitumor efficacy [105]. LPDp achieved the optimal tumor suppression efficiency $(\sim 78.7 \%)$ due to synergistic contribution of chemotherapeutic agents and the blockade of immune checkpoints. Lu et al. [106] have established a liposome for co-loading DOX and IDO-1 inhibitor indoximod (IND) for chemoimmunotherapy (DOX/ IND-liposome). DOX/IND-liposome was self-assembled by phospholipid-conjugated IND, followed by the remote DOX loading (Fig. 3). The results demonstrated that DOX/INDliposomes enhanced the anti-breast cancer immune response significantly than DOX-liposomes.

\subsection{Polymer Micelles}

Polymer micelles are thermodynamically stable colloidal solutions formed by self-assembly of amphiphilic block 
Table 4 Summary of NDDS for "co-encapsulation" approach in chemoimmunotherapy

\begin{tabular}{|c|c|c|c|c|}
\hline Type of carrier & Chemotherapy drug & Immunotherapy & $\begin{array}{l}\text { In vitro cell line or in vivo tumor } \\
\text { model }\end{array}$ & References \\
\hline Liposomes & Doxorubicin & PD-L1 inhibitor & $\begin{array}{l}\text { B16F10 tumor-bearing C57BL/6 } \\
\text { mice }\end{array}$ & {$[105]$} \\
\hline Liposomes & Doxorubicin & Indoximod & $\begin{array}{l}\text { 4T1 cells orthotopic breast cancer } \\
\text { models }\end{array}$ & [106] \\
\hline Liposomes & Docetaxel & PD-L1 mAb & $\begin{array}{l}\text { B16-F10 cells xenograft tumor } \\
\text { animal model }\end{array}$ & [104] \\
\hline Polymer micelles & All-trans retinoic acid & PD-L1 mAb & $\mathrm{C} 3 \mathrm{H}$ tumor-bearing mice & [128] \\
\hline Polymer micelles & Dacarbazine & $\mathrm{DR} 5 \mathrm{mAb}$ & A375 cells and NIH cells & [163] \\
\hline Polymer micelles & Dacarbazine & $\mathrm{DR} 5 \mathrm{mAb}$ & $\begin{array}{l}\text { A375 BALB/c nude mouse tumor } \\
\text { model }\end{array}$ & [164] \\
\hline Polymer micelles & Paclitaxel & HY19991 & MCF-7 tumor-bearing mice & [137] \\
\hline Polymer micelles & Curcumin & NLG919 & $\begin{array}{l}\text { B16F10 tumor-bearing C57BL/6 } \\
\text { mice }\end{array}$ & [129] \\
\hline Polymer micelles & Paclitaxel & PD-L1 mAb & $\begin{array}{l}\text { B16F10 tumor-bearing C57BL/6 } \\
\text { mice }\end{array}$ & {$[107]$} \\
\hline Polymer micelles & $\mathrm{Pt}(\mathrm{IV})$ prodrug & $\operatorname{poly}(\mathrm{I}: \mathrm{C})$ & PC3, MDA-MB231, PANC-1 cells & [108] \\
\hline Dendrimers & Doxorubicin & $\mathrm{CpG}$ & 22RV1 cells BALB/mice & [109] \\
\hline Dendrimers & Doxorubicin & $\mathrm{CpG}$ & B16-F10 melanoma-bearing mice & {$[110]$} \\
\hline Dendrimers & Platinum & BLZ-945 & $\begin{array}{l}\text { CT26 colon cancer, B16 mela- } \\
\text { noma models and } 4 \text { T1 tumor- } \\
\text { bearing mice }\end{array}$ & [111] \\
\hline Black phosphorus NPs & Doxorubicin & $\begin{array}{l}\text { PD-L1 mAb/small interfering } \\
\text { RNA }\end{array}$ & MC-38 tumor-bearing mice & [112] \\
\hline CuS NPs & Docetaxel & $\mathrm{CpG}$ & Negative breast cancers & [113] \\
\hline Hydrogel & Celecoxib & Anti-PD-1 mAb & $\begin{array}{l}\text { B16-F10 melanoma and 4T1 } \\
\text { metastatic breast cancer }\end{array}$ & [149] \\
\hline Hydrogel & Cisplatin & IL-15 & B16-F10 melanoma-bearing mice & [114] \\
\hline Nanogel & Docetaxel & NLG919 & $\begin{array}{l}\text { 4T1-Luc murine breast cancer } \\
\text { xenograft mouse model }\end{array}$ & {$[150]$} \\
\hline Hydrogel & Doxorubicin & $\mathrm{CpG}$ & B16 melanoma-bearing mice & [115] \\
\hline Hydrogel & Doxorubicin & IL-2/IFN-g & B16-F10 melanoma-bearing mice & {$[151]$} \\
\hline Hydrogel & Doxorubicin & melittin-RADA32 & B16-F10 melanoma-bearing mice & {$[152]$} \\
\hline Albumin biomimetic NPs & Temozolomide & Regorafenib & $\begin{array}{l}\text { U87 orthotopic glioma-bearing } \\
\text { mice }\end{array}$ & {$[153]$} \\
\hline HLD-biomimetic nanodiscs & Docetaxel & $\mathrm{CpG}$ & Glioblastoma & [116] \\
\hline Lactoferrin NPs & Shikonin & JQ1 & CT26 tumor-bearing mice & {$[154]$} \\
\hline $\begin{array}{l}\text { Erythrocyte membrane biomimetic } \\
\text { NPs }\end{array}$ & Paclitaxel & IL-2 & B16-F10 melanoma-bearing mice & [118] \\
\hline $\begin{array}{l}\text { Tumor cell membrane biomimetic } \\
\text { NPs }\end{array}$ & Doxorubicin & Surface-layer protein (adjuvant) & B16-F10 melanoma-bearing mice & [117] \\
\hline $\begin{array}{l}\text { NK cell membrane biomimetic } \\
\text { NPs }\end{array}$ & Oxaliplatin & 1-Methyl-D-tryptophan & 4T1 tumor-bearing mice & {$[160]$} \\
\hline
\end{tabular}

copolymers [120]. Hydrophobic small-molecule drugs could be encapsulated in the hydrophobic core of micelles, and hydrophilic drugs could be loaded via physical interactions or chemical conjugation [121]. Genexol ${ }^{\circledR}$-loaded PTX and Nanoxel ${ }^{\circledR}$-loaded docetaxel (DTX) have been approved for the cancer treatment. Polymer micelles have been widely evaluated in cancer chemoimmunotherapy. Furthermore, the multifunctional polymer micelles can be obtained by modification on the surface of polymeric materials, which could package hydrophilic or 
(a)
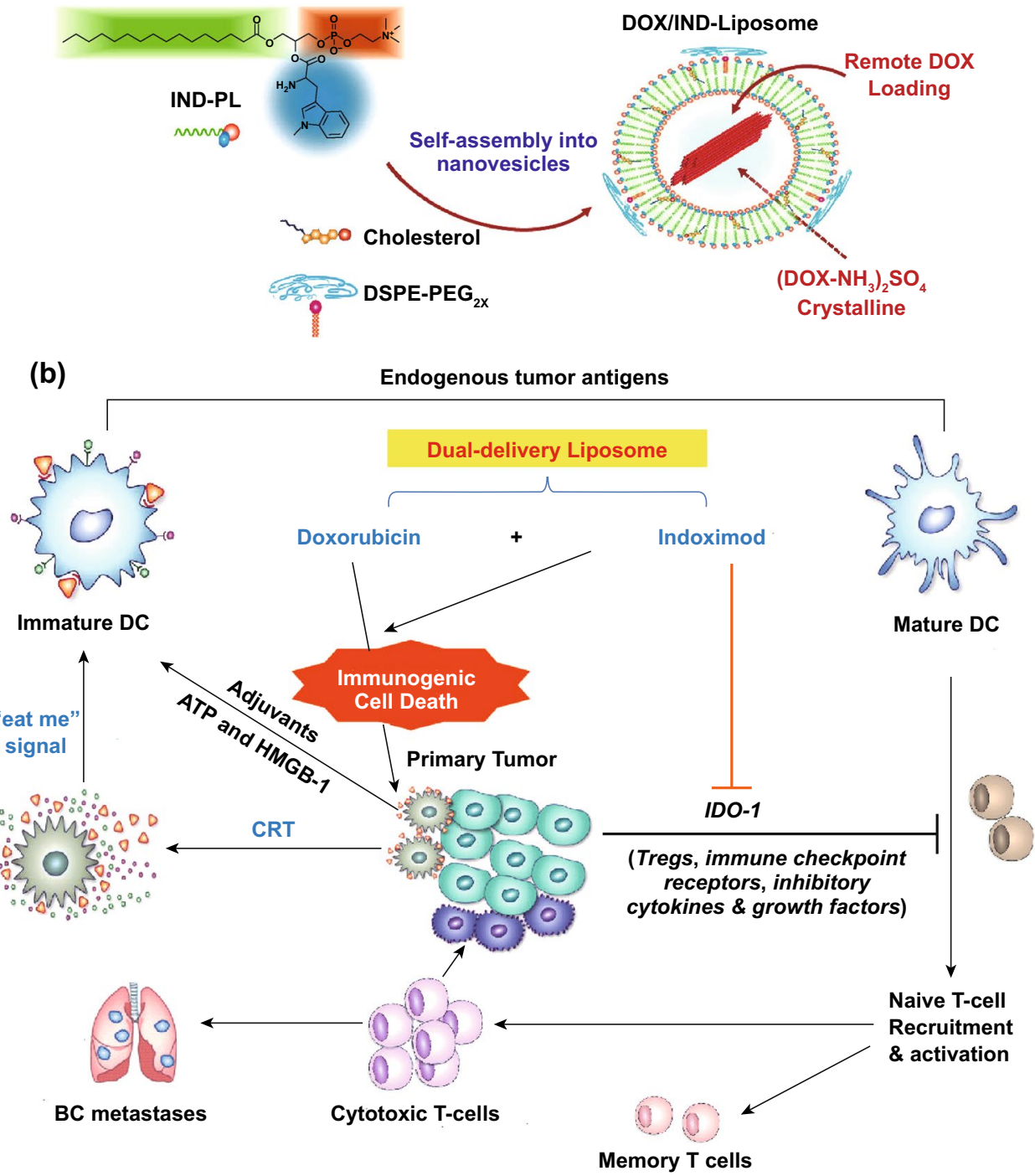

Fig. 3 a Synthesis of DOX/IND-liposome, b Illustration of breast cancer immunotherapy by combined delivery of DOX plus IND. Reproduced with permission from Ref. [106]. Copyright 2018 American Chemical Society

hydrophobic drugs efficiently and protect them from degradation in vitro and in vivo.

PLGA and polylactic acid (PLA) are FDA approved polymers materials with biodegradable and biocompatible features [122-124]. Polymer micelles prepared from PLGA/PLA have been evaluated as drug carriers in chemoimmunotherapy [125-127]. For example, Zhou et al. [128] have developed a PLGA-PEG micelle co-delivering all-trans retinoic acid (ATRA) and PD-L1 mAb for the treatment of oral dysplasia and oral squamous cell carcinoma. Antitumor assay in vivo demonstrated that the ATRA-PLGA-PEG-PD-L1 had superior therapeutic efficacy than free ATRA and $\mathrm{CD} 8^{+} \mathrm{T}$ cells were activated in TME after treatment.

Other multifunctional polymer micelles were also explored to improve the efficacy of chemoimmunotherapy. Xintao Shuai and his group designed $\mathrm{pH}$ and MMP-2 dualsensitive micelles to co-deliver anti-PD-1 antibody (aPD-1) and PTX for synergistic cancer chemoimmunotherapy [107]. The micelles showed an enhanced tumor chemoimmunotherapy effect in murine melanoma model. Juan C. MarequeRivas and co-workers reported Pt(IV) prodrug-modified PEGylated phospholipid micelles that encapsulate iron oxide NPs (IONPs), which were functionalized with poly 
(I:C) for chemoimmunotherapy (poly (I:C)-Pt(IV)-IONPs) (Fig. 4) [108]. The poly (I:C)-Pt(IV)-IONPs enhanced cytotoxicity in different tumor cells significantly and activated DC by cisplatin and poly (I:C) in immunotherapy greatly. In a study by Yang et al., size-shrinkage and charge-reversal micelles co-loaded IDO inhibitor NLG919 and curcumin (CUR) were developed (PCPCD) [129]. PCPCD showed high efficiency of inhibiting tumor growth, metastasis and recurrence in vivo by the combined effects of chemotherapy-enhanced immunogenicity, and NLG919-induced IDOblockade immunotherapy.

\subsection{Dendrimers}

Dendrimers are hyperbranched spherical polymers formed of a hydrophobic central core, branched monomer and functional peripheral groups [130]. With the unique structural features of dendrimers, such as structural clarity, close-to-monodisperses, ease of multi functionalities and multivalences, numerous novel dendrimer-based NPs have been designed and attracted scientific attention [131-133]. The hydrophobic central core could be loaded with small molecular drugs and the functional peripheral group can chemically link immunotherapy agents, such as therapeutic antibody. At present, the most widely used dendrimers are polyamidoamine (PAMAM), polypropyleneimine (PEI) and peptide dendrimers.
At present, several dendrimers have reached clinical trials for cancer immunotherapy, and they also have high application prospect in chemoimmunotherapy [109, 134-136]. He et al. [110] designed a PAMAM-based chemoimmunotherapy NPs (LMWH/PPD/CpG) by co-loading DOX and $\mathrm{CpG}$ for the treatment of metastatic melanoma. DOX conjugated on the amino-terminated PAMAM dendrimer by $\mathrm{pH}$ sensitive hydrazone bond (PPD). LMWH/PPD/CpG were formed by negatively charged low molecular weight heparin (LMWH) coating on the surface of PAMAM. LMWH/ $\mathrm{PPD} / \mathrm{CpG}$ showed enhanced immune response in vivo and increased antitumor efficacy against melanoma (Fig. 5).

Currently, new dendrimers-based NPs have been used to achieve the deep penetration of loaded drugs for efficient chemoimmunotherapy [137]. Wang et al. reported a $\mathrm{pH}$ sensitive poly(ethylene glycol)- $b$-poly(2-azepane ethyl methacrylate) amphiphilic block copolymer (PEG- $b$-PAEMA), which was further modified with PAMAM/Pt to obtain PEG$b$-PAEMA-PAMAM/Pt NPs (SCNs/Pt) (Fig. 6a) [138]. The $\mathrm{SCNs} / \mathrm{Pt}$ could achieve ultrasensitive size switching in the acidic TME for improved tumor penetration in vivo. Then, the SCNs was used for loading BLZ-945 (small-molecule inhibitor of CSF-1R of TAMs) and Pt-based prodrug NPs ${ }^{\text {BLZ- } 945}{ }^{S C N s} / \mathrm{Pt}$ (Fig. 6b) [111]. Antitumor study in vivo showed that ${ }^{B L Z-945} \mathrm{SCNs} / \mathrm{Pt}$ could inhibit the tumor growth more effectively, compared with ${ }^{B L Z-945} \mathrm{SCNs}$ or SCNs/Pt monotherapy. (a)

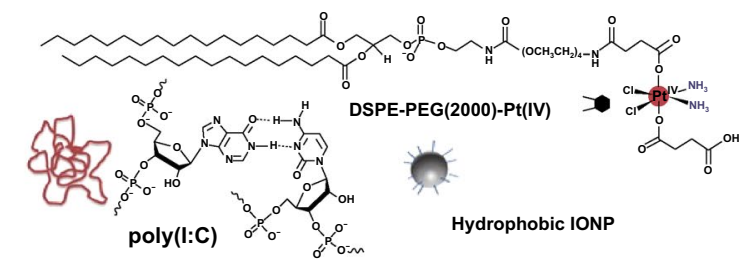

(b)

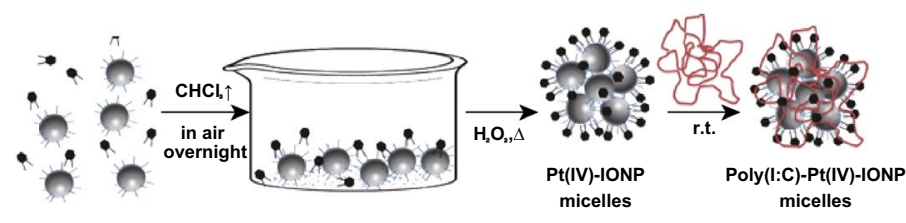

(c)

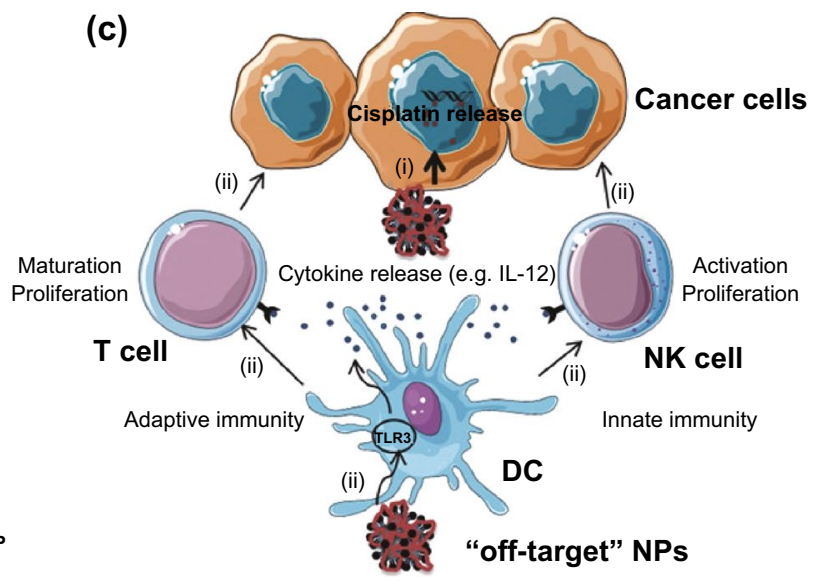

Fig. 4 Preparation of the poly (I:C)-Pt(IV)-IONP micelles. a Structure and schematic representation of the reaction components and $\mathbf{b}$ schematic of the simple self-assembly procedure used to prepare the Pt(IV)-IONP micelles and poly (I:C)-Pt(IV)-IONP micelles (not to scale). c Schematic illustration of the combination therapeutic effect of poly (I:C)-Pt(IV)-IONPs. Reproduced with permission from Ref. [108]. Copyright 2015 John Wiley and Sons 


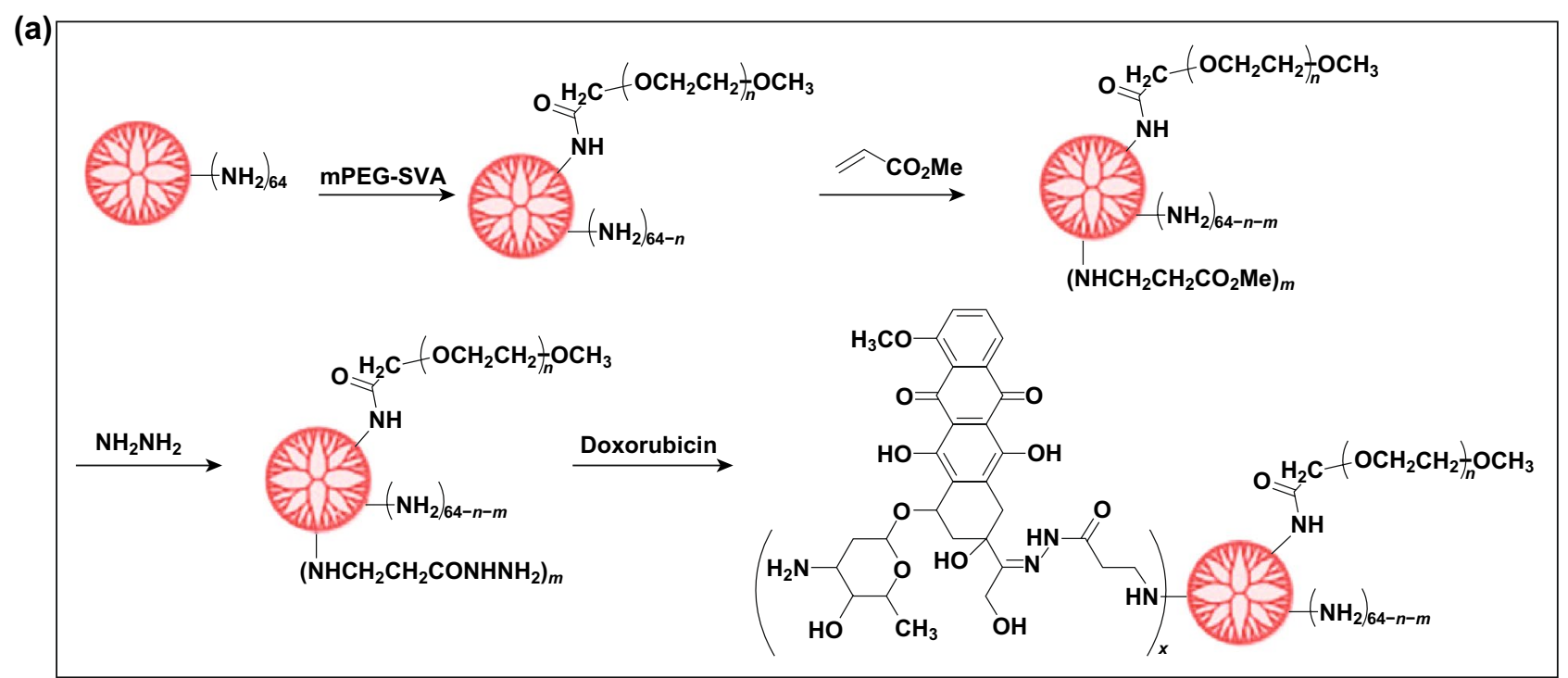

(b)

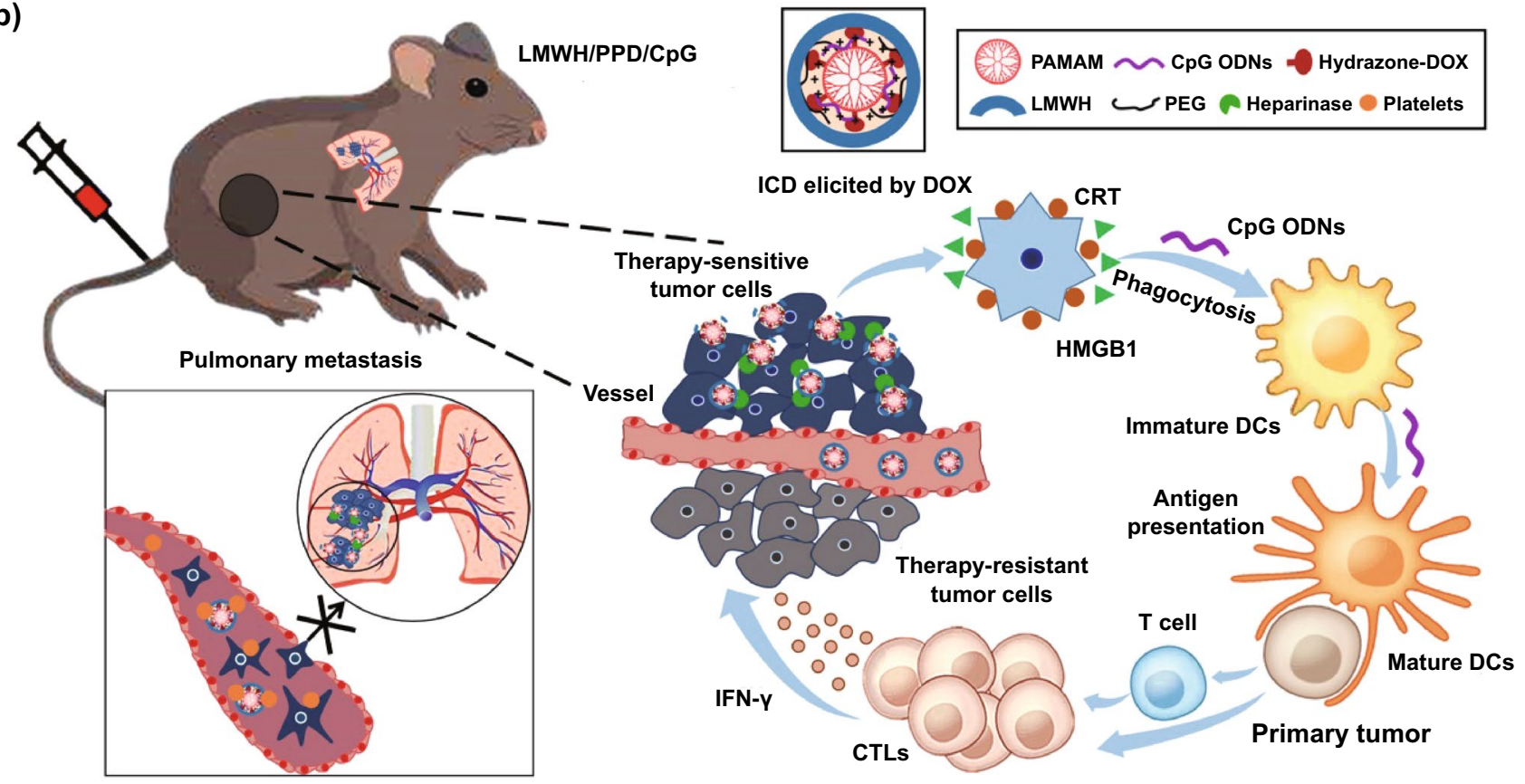

Fig. 5 a Schematic illustration of reaction scheme for the synthesis of pH-sensitive hydrazone bond linked PEG-PAMAM-DOX conjugates (PPD). b Schematic illustration of LMWH/PPD/CpG to inhibit melanoma tumor. Reproduced with permission from Ref. [110]. Copyright 2019 lvyspring International Publisher

\subsection{Metallic and Inorganic NPs}

Metallic and inorganic NPs have shown favorable advantages as drug carriers, such as high drug loading capacity, feasibility of functionalization and no immunogenicity. A large number of metallic and inorganic NPs have been investigated for chemoimmunotherapy, including graphene oxide-based NPs (GO NPs) [139], mesoporous silica NPs (MSN NPs) [140-143], black phosphorus (BP) NPs [112], gold NPs (AuNPs), copper-derived NPs (Cu NPs) and so on $[144,145]$.

Taking BP as an example, BP is a new member of twodimensional materials, nonmetallic-layered semiconductor with corrugated crystalline and textural properties. The 
(a)
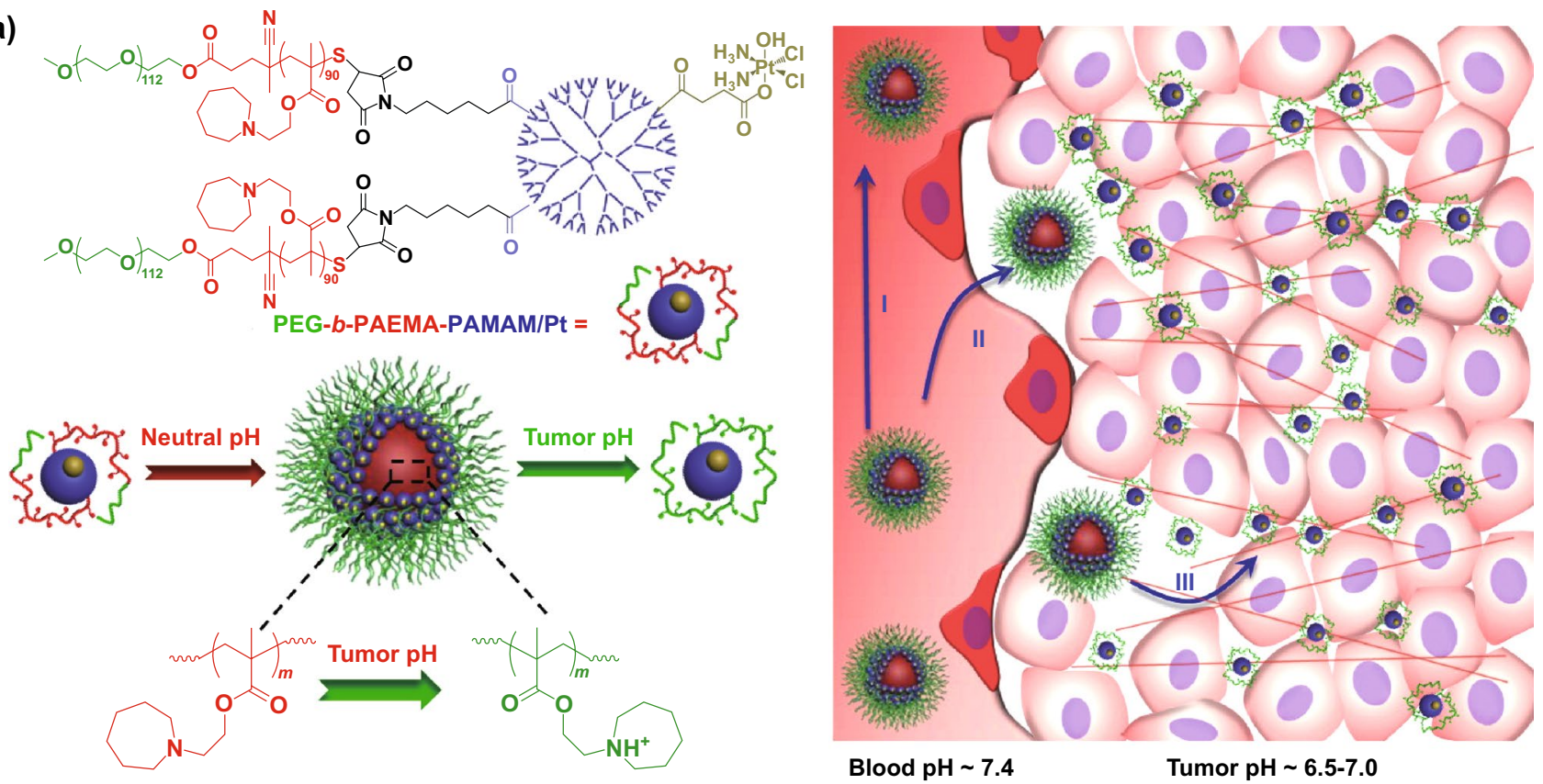

(b)
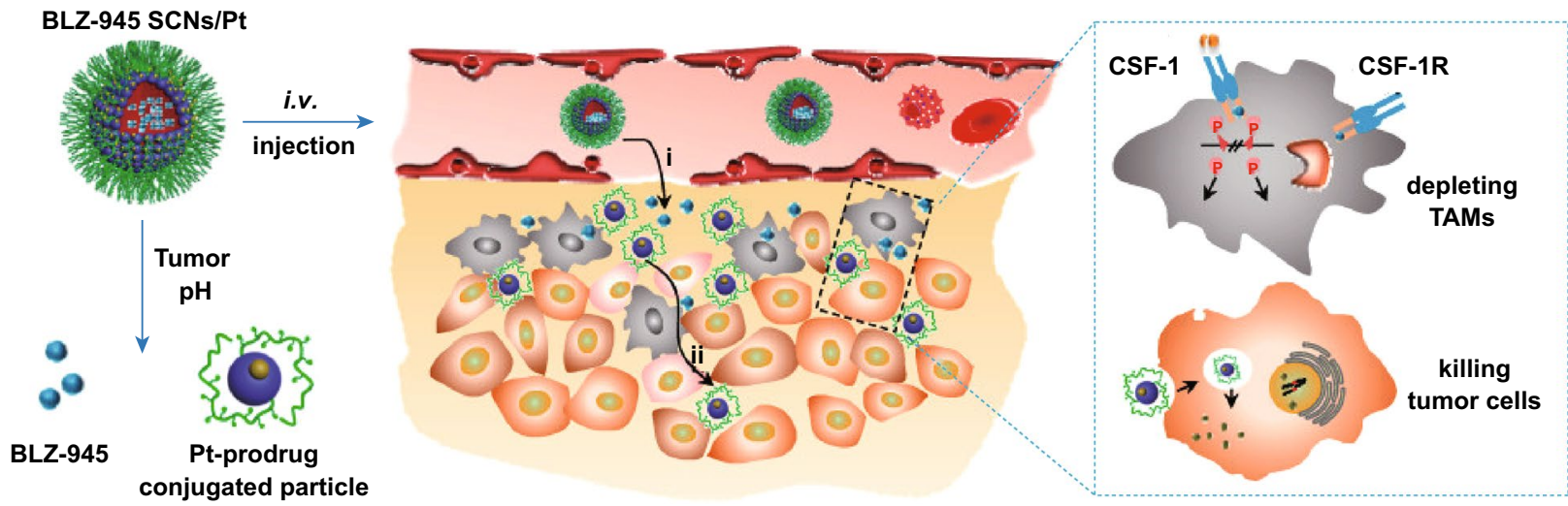

Fig. 6 a Schematic illustration of PEG-b-PAEMA-PAMAM/Pt, reproduced with permission from Ref. [138]. Copyright 2016 American Chemical Society. b Mechanism of spatial delivery of BLZ-945 and Pt-prodrug to TAMs and tumor cells. Reproduced with permission from Ref. [111]. Copyright 2017 American Chemical Society

unique structure enables BP has special properties, such as huge surface area, good mechanical flexibility, ultra-high photothermal conversion efficiency, good biocompatibility and biodegradability. BP showed a good prospect in photoacoustic imaging, photothermal therapy [146], photodynamic therapy and drug loading for chemoimmunotherapy [145, 147]. For example, Jong Oh Kim and co-workers reported coarse BP flakes with plug-and-play and ultrasonic bubble bursting features to load DOX, programmed death ligand 1 and small interfering RNA (BP-DcF@ @PL) for chemo-photoimmunotherapy of colorectal cancer [112]. BP-DcF@sPL showed significantly prolonged and lasted survival period in MC-38 tumor xenografted in C57BL/6 mouse models.

Metallic material-derived NPs usually have photothermal therapy (PTT) and photodynamic therapy (PDT) effects, which not only can be used as photosensitizer, but also have great potential for cancer immunotherapy due to ICD. For example, Chunyan Dong and his group designed a multifunctional NPs FA-CuS/DTX@PEI-CpG NPs (FA-CD@ PP-CpG) for synergistic PDT, PTT and DTX-enhanced immunotherapy [113]. FA-CD@PP-CpG can improve immunotherapy effect, such as promote infiltration of 
CTLs, suppress MDSCs and enhance antitumor efficacy on 4T1-tumor-bearing mice (Fig. 7).

\subsection{Nanogels}

Nanogels, with nano-sized hydrogel scaffold, good biocompatibility, high water contents and great compatibility with various therapeutic agents (such as small-molecule drugs and bio-macromolecules) have been considered as promising NDDS for effective chemoimmunotherapy. Multifunctional nanogels could be rationally designed for chemoimmunotherapy, by decorating with targeting ligands, synthesizing responsive functional bonds and so on [114, 115, 148-150]. For example, Chen et al. have reported a thermo-sensitive hydrogel co-loaded DOX/IL-2/IFN- $\gamma$, which showed improved therapeutic efficacy B16F10 melanoma tumor by enhancing tumor cell apoptosis and increasing proliferation of the $\mathrm{CD}^{+} / \mathrm{CD}^{+}{ }^{+} \mathrm{T}$ cells and $\mathrm{CD}^{+} /$ $\mathrm{CD}^{+} \mathrm{T}$ cells [151]. Special hydrogel systems may have the ability for immune-stimulating. For example, Yang et al. have reported a melittin-RADA 32 hydrogel-loaded DOX (MRD) for chemoimmunotherapy through active regulation of TMEs [152]. The melittin-RADA 32 peptide, denoted as MR peptide, was a building block of the peptide hydrogel. Melittin is a cationic peptide derived from bee venom with the sequence GIGAVLKVLTTGLPALISWIKRKRQQ. The sequence of melittin-RADA 32 was RADARADARADARADARADARADARADA-RADA-GG-GIGAVLKVLTTGLP-

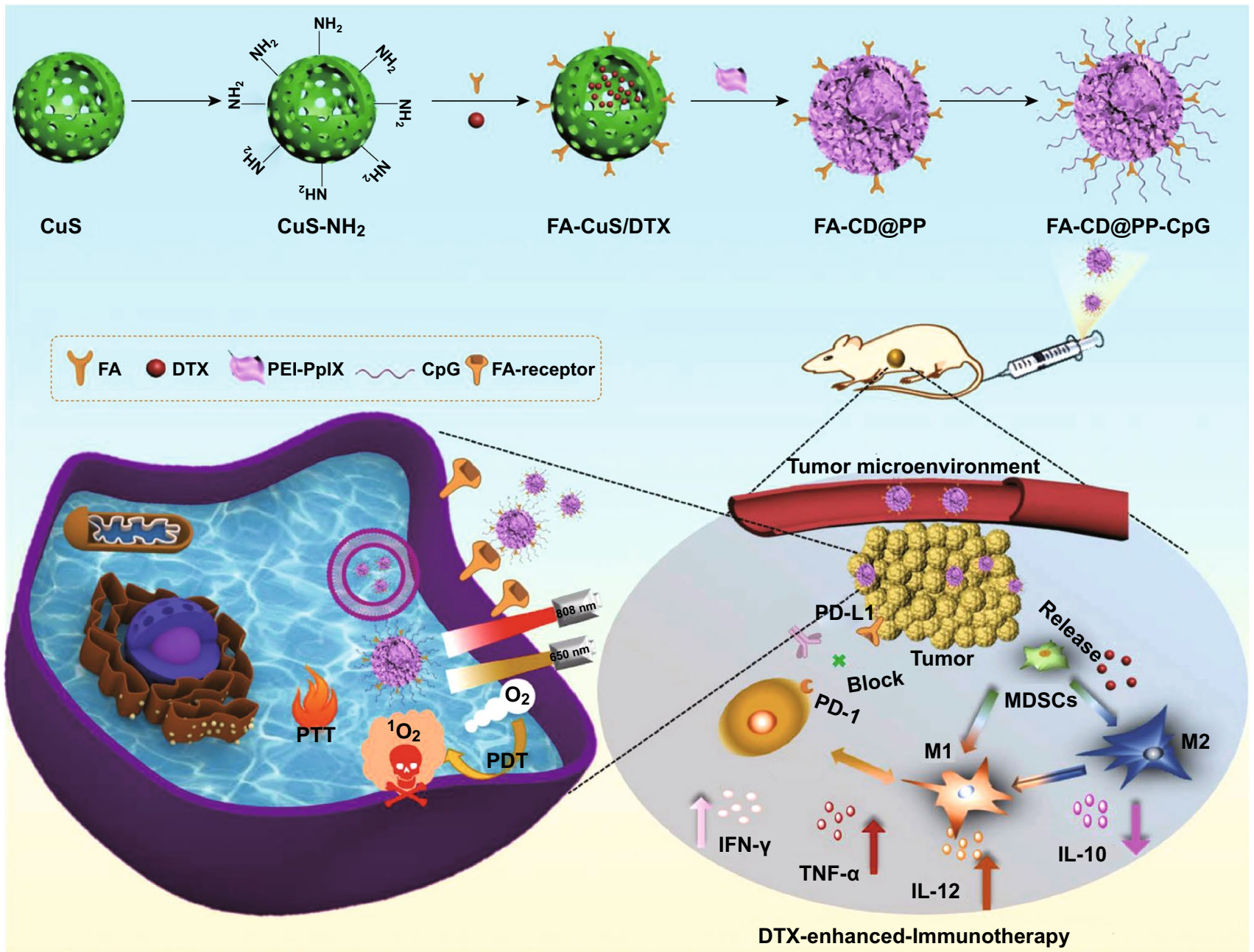

Fig. 7 Scheme of the rational design and synthesis of FA-CD@PP-CpG and illustration of FA-CD@PP-CpG for DTX-enhanced immunotherapy. Reproduced with permission from Ref. [113]. Copyright 2019 John Wiley and Sons 
ALISWIKRKRQQ-NH2, in which melittin is linked to RADA $_{32}$ through a GG linker. MRD showed enhanced killing effect to melanoma tumors by controlling drug release, regulating innate immune cells and depleting M2-type TAMs (Fig. 8).

\subsection{Biomimetic NPs}

Biomimetic NPs have been designed to mimic natural organisms/structures through coating or mixing biocompatibility materials, which could camouflage of NPs as autologous components to escape the clearance of the immune system. Biomimetic NPs have the morphology, surface properties and size of natural structures (such as red blood cells, exosomes), which have enhanced targeting ability to deliver drugs to target cells or tissues, good biocompatibility, improved treatment efficiency and reduced side effects.

Proteins, such as albumin [153], high-density lipoproteins (HDL) [116], low-density lipoproteins (SDL), transferrin family proteins and their-derived proteins [154] have been applied to biomimetic NPs for chemoimmunotherapy. For example, HLD are involved in cholesterol and molecule transport, which could target specific cells. Anna Schwendeman et al. reported an HDL-mimicking nanodiscs loaded with CpG and DTX (DTX-sHDL-CpG) against glioblastoma multiforme (GBM). DTX-sHDL-CpG showed tumor inhibition and long-term survival in GBM tumor-bearing mice when combined with radiation [116]. The sHDL nanodisc was an effective NDDS for chemoimmunotherapy.

Cell membrane biomimetic NPs are mainly composed of cell membrane coating functional NPs. The proteins on the cell membranes derived from different cells still retain bioactive, thus giving them the ability to immune escape, prolonged blood circulation time and tumor targeting $[155,156]$. Currently, cell membranes of biomimetic NPs mainly include erythrocyte, leukocytes, platelets, neutrophils, macrophages, $\mathrm{T}$ lymphocytes, stem cells and tumor cells [157-159]. Different cell membranes make biomimetic NPs have different functions in cancer therapy. Erythrocyte membrane biomimetic NPs could improve biocompatibility and biodegradability and prolong blood circulation [118]. For example, Zhiping Zhang and his group have developed erythrocyte membrane-coated nanogels $\left(\mathrm{NR}_{\mathrm{P}+\mathrm{I}}\right)$ for PTX and IL-2 co-delivery and controlled release in TME (Fig. 9) [118]. The inner core nanogels were consisted of two opposite charged chitosan derivatives and 2 -hydroxypropyl- $\beta$-cyclodextrin (HP- $\beta$-CD), which was for PTX loading and controlled release. The $\mathrm{pH}$-responsive capability to acidic TME could be precisely controlled by adjusting the formulation of nanogel. The erythrocyte membrane was further coated on the nanogel for the delivery of IL-2. PTX may be controllable and $\mathrm{pH}$-responsive released with the help of HP- $\beta$-CD and chitosan in TME. After losing the support of

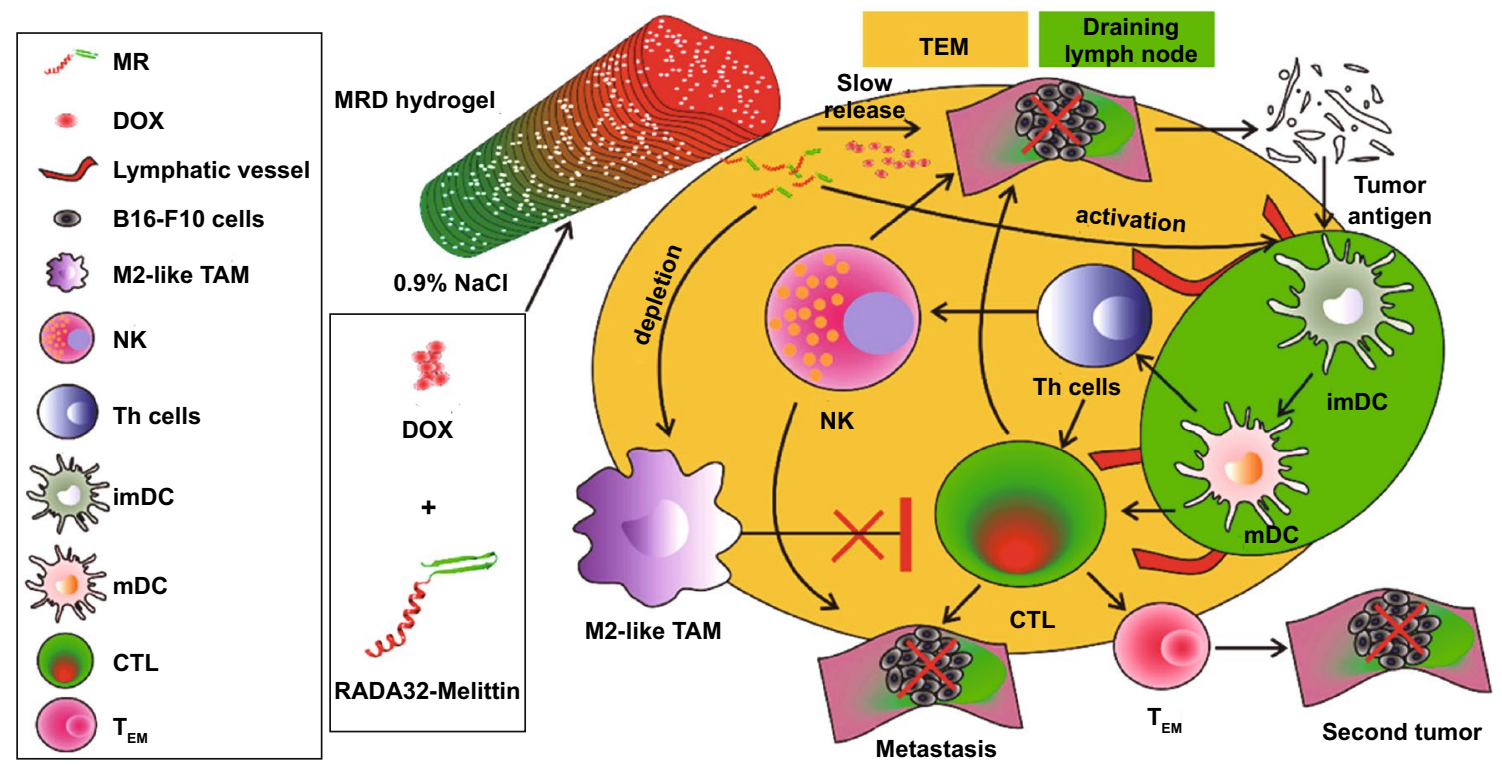

Fig. 8 Mechanism of MRD hydrogel-mediated antitumor effects against melanoma. Reproduced with permission from Ref. [152]. Copyright 2018 American Chemical Society 


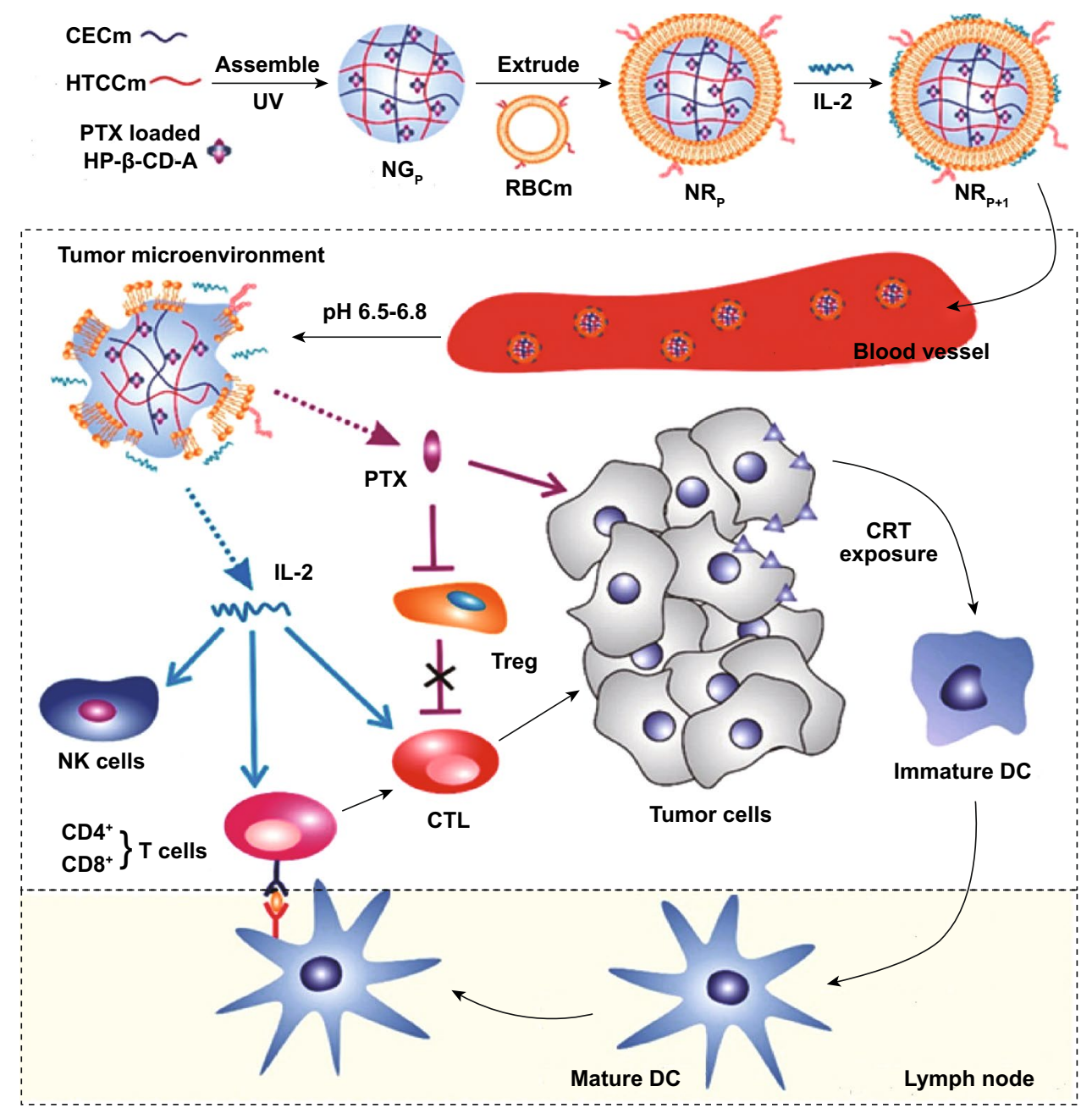

Fig. 9 Schematic illustration $\mathrm{NR}_{\mathrm{P}+\mathrm{I}}$ for chemoimmunotherapy. Reproduced with permission from Ref. [118]. Copyright 2017 American Chemical Society

inner core, the membrane could be disintegrated to constantly release IL-2 into TME. $\mathrm{NR}_{\mathrm{P}+\mathrm{I}}$ showed enhanced antitumor activity with increased antitumor immunity and improved drug penetration. Tumor cell membrane biomimetic NPs have homologous targeting and homology adhesion, which enable its specific recognition and aggregation in tumor tissue [117]. Lymphocytes membrane biomimetic NPs could retain the ability to migrate to tumor sites and prolong circulation time in the body [160].

\section{Conclusion}

The clinical and preclinical results uphold the rationality for the combination of chemotherapy and immunotherapy. Combining immunotherapy agents with chemotherapeutic drugs has great potentials as long-term maintenance therapy for cancer to maximize the synergistic antitumor effects. When designing a rational prescription for combinational chemoimmunotherapy in clinics, the 
administration dosages, intervals as well as cycles should be strategically considered to avoid iRAE effectively. NDDS provides a favorable platform in promoting the efficacy of chemoimmunotherapy, and numerous multifunctional NDDS have been designed up to now. These NDDS designed for chemoimmunotherapy showed many advantages, including increased solubility and bioavailability of both chemotherapy drugs and immunotherapy agents, prolonged circulation time in vivo, increased the accumulation of therapeutic agents in tumor site by specific-targeting and improved pharmacokinetics behaviors in vivo, thus significantly enhancing the therapeutic effects even at low-dose chemotherapeutic agents and reducing the side effects.

Despite NDDS-exhibited superiority in interrupting tumor immune balance, eliminating tumors and inhibiting metastasis, increased accumulation of immunotherapy agents at the tumor site might induce immunogenicity or autoimmune diseases and increase the occurrence of iRAE. Furthermore, chemotherapeutic agents and immunotherapy agents usually have different target cells, co-encapsulation strategies are difficult to achieve separate delivery to different cells in tumor tissue, which may unconsciously increase the off-target effect. Timing and quantitative controlled release of different drugs with precision targeting to different cells provide a new direction for the improvement in cancer chemoimmunotherapy or even immune-related multimodal-therapy. Otherwise, the clinical translation of NDDS are still facing significant obstacles due to complex processes, unavoidable drug leakage, undefined safety in excipients and undesired stability etc. In view of this, NDDS with simple prescription, mature preparation process and good biocompatibility are urgently pursued for higher clinical translation prospects. In a word, the combinational chemoimmunotherapy still has a long way to conquer in cancer treatment, and NDDS may play a crucial role in exerting their unique advantages.

Acknowledgements This work is supported by the National Natural Science Foundation of China (No. 81974498, No. 81773652). A special thanks to Prof. Zhiyue Zhang for the support of English grammar corrections.

Open Access This article is licensed under a Creative Commons Attribution 4.0 International License, which permits use, sharing, adaptation, distribution and reproduction in any medium or format, as long as you give appropriate credit to the original author(s) and the source, provide a link to the Creative Commons licence, and indicate if changes were made. The images or other third party material in this article are included in the article's Creative Commons licence, unless indicated otherwise in a credit line to the material. If material is not included in the article's Creative Commons licence and your intended use is not permitted by statutory regulation or exceeds the permitted use, you will need to obtain permission directly from the copyright holder. To view a copy of this licence, visit http://creativecommons.org/licenses/by/4.0/.

\section{References}

1. R.L. Siegel, K.D. Miller, A. Jemal, Cancer statistics, 2016. CA Cancer J. Clin. 66, 7-30 (2016). https://doi. org/10.3322/caac. 21332

2. F. Bray, J. Ferlay, I. Soerjomataram, R.L. Siegel, L.A. Torre, A. Jemal, Global cancer statistics 2018: GLOBOCAN estimates of incidence and mortality worldwide for 36 cancers in 185 countries. CA Cancer J. Clin. 68(6), 394-424 (2018). https://doi.org/10.3322/caac.21492

3. A.B. Miller, B. Hoogstraten, M. Staquet, A. Winkler, Reporting results of cancer treatment. Cancer 47, 207214 (1981). https://doi.org/10.1002/1097-0142(19810 101)47:1\%3c207:AID-CNCR2820470134\%3e3.0.CO;2-6

4. T.A. Waldmann, Immunotherapy: past, present and future. Nat. Med. 9, 269-277 (2003). https://doi.org/10.1038/nm030 3-269

5. M. McNutt, Cancer immunotherapy. Science 342, 1417 (2013). https://doi.org/10.1126/science.1249481

6. T. Jiang, C. Zhou, The past, present and future of immunotherapy against tumor. Transl. Lung Cancer R 4, 253-264 (2015). https://doi.org/10.3978/j. issn.2218-6751.2015.01.06

7. K. Esfahani, L. Roudaia, N. Buhlaiga, S.V. Del Rincon, N. Papneja, W.H. Miller Jr., A review of cancer immunotherapy: from the past, to the present, to the future. Curr. Oncol. 27, S87-S97 (2020). https://doi.org/10.3747/co.27.5223

8. I. Mellman, G. Coukos, G. Dranoff, Cancer immunotherapy comes of age. Nature 480, 480-489 (2011). https://doi. org/10.1038/nature10673

9. D.M. Pardoll, The blockade of immune checkpoints in cancer immunotherapy. Nat. Rev. Cancer 12, 252-264 (2012). https://doi.org/10.1038/nrc3239

10. Y. Li, F. Li, F. Jiang, X. Lv, R. Zhang, A. Lu, G. Zhang, A mini-review for cancer immunotherapy: molecular understanding of PD-1/PD-L1 pathway \& translational blockade of immune checkpoints. Int. J. Mol. Sci. 17(7), 1151 (2016). https://doi.org/10.3390/ijms17071151

11. A.C. Anderson, N. Joller, V.K. Kuchroo, Lag-3, Tim-3, and TIGIT: co-inhibitory receptors with specialized functions in immune regulation. Immunity 44, 989-1004 (2016). https://doi.org/10.1016/j.immuni.2016.05.001

12. C.R. Parish, Cancer immunotherapy: the past, the present and the future. Immunol. Cell Biol. 81, 106-113 (2003). https://doi.org/10.1046/j.0818-9641.2003.01151.x 
13. G. Chen, L.A. Emens, Chemoimmunotherapy: reengineering tumor immunity. Cancer Immunol. Immun. 62, 203216 (2013). https://doi.org/10.1007/s00262-012-1388-0

14. A.K. Nowak, W.J. Lesterhuis, Chemoimmunotherapy: still waiting for the magic to happen. Lancet Oncol. 15, 780-781 (2014). https://doi.org/10.1016/S1470-2045(14)70267-0

15. D.M. Francis, S.N. Thomas, Progress and opportunities for enhancing the delivery and efficacy of checkpoint inhibitors for cancer immunotherapy. Adv. Drug Deliv. Rev. 114, 33-42 (2017). https://doi.org/10.1016/j.addr.2017.04.011

16. A.M. Cook, W.J. Lesterhuis, A.K. Nowak, R.A. Lake, Chemotherapy and immunotherapy: mapping the road ahead. Curr. Opin. Immunol. 39, 23-29 (2016). https://doi.org/10.1016/j. coi.2015.12.003

17. L. Galluzzi, L. Senovilla, L. Zitvogel, G. Kroemer, The secret ally: immunostimulation by anticancer drugs. Nat. Rev. Drug Discov. 11, 215-233 (2012). https://doi.org/10.1038/nrd3626

18. Y.L. Chen, M.C. Chang, W.F. Cheng, Metronomic chemotherapy and immunotherapy in cancer treatment. Cancer Lett. 400, 282-292 (2017). https://doi.org/10.1016/j.canle t.2017.01.040

19. S. Goel, M.J. DeCristo, A.C. Watt, H. BrinJones, J. Sceneay et al., CDK4/6 inhibition triggers anti-tumour immunity. Nature 548, 471-475 (2017). https://doi.org/10.1038/nature23465

20. N.K. Egilmez, J.L. Harden, R.B. Rowswell-Turner, Chemoimmunotherapy as long-term maintenance therapy for cancer. Oncoimmunology 1(4), 563-565 (2012). https://doi. org/10.4161/onci.19369

21. C. He, Z. Tang, H. Tian, X. Chen, Co-delivery of chemotherapeutics and proteins for synergistic therapy. Adv. Drug Deliv. Rev. 98, 64-76 (2016). https://doi.org/10.1016/j. addr.2015.10.021

22. C.M. Hu, S. Aryal, L. Zhang, Nanoparticle-assisted combination therapies for effective cancer treatment. Ther. Deliv. 1, 323-334 (2010). https://doi.org/10.4155/tde.10.13

23. C.G. Da Silva, F. Rueda, C.W. Lowik, F. Ossendorp, L.J. Cruz, Combinatorial prospects of nano-targeted chemoimmunotherapy. Biomaterials 83, 308-320 (2016). https://doi. org/10.1016/j.biomaterials.2016.01.006

24. T. Shao, X. Li, J. Ge, Target drug delivery system as a new scarring modulation after glaucoma filtration surgery. Diagn. Pathol. 6, 64 (2011). https://doi.org/10.1186/1746-1596-6-64

25. D.S. Chen, I. Mellman, Oncology meets immunology: the cancer-immunity cycle. Immunity 39, 1-10 (2013). https:// doi.org/10.1016/j.immuni.2013.07.012

26. C.H. Kapadia, J.L. Perry, S. Tian, J.C. Luft, J.M. DeSimone, Nanoparticulate immunotherapy for cancer. J. Control. Release 219, 167-180 (2015). https://doi.org/10.1016/j.jconr el.2015.09.062

27. B.D. Cheson, J.P. Leonard, Monoclonal antibody therapy for B-cell non-Hodgkin's lymphoma. New Engl. J. Med. 359, 613-626 (2008). https://doi.org/10.1056/NEJMra0708875

28. A.M. Scott, J.D. Wolchok, L.J. Old, Antibody therapy of cancer. Nature reviews. Cancer 12, 278-287 (2012). https://doi. org/10.1038/nrc3236
29. P. Sharma, J.P. Allison, The future of immune checkpoint therapy. Science 348, 56-61 (2015). https://doi.org/10.1126/ science.aaa8172

30. A.W. Hahn, D.M. Gill, S.K. Pal, N. Agarwal, The future of immune checkpoint cancer therapy after PD-1 and CTLA-4. Immunotherapy 9, 681-692 (2017). https://doi.org/10.2217/ imt-2017-0024

31. C. Robert, L. Thomas, I. Bondarenko, S. O'Day, J. Weber et al., Ipilimumab plus dacarbazine for previously untreated metastatic melanoma. New Engl. J. Med. 364, 2517-2526 (2011). https://doi.org/10.1056/NEJMoa1104621

32. C. Kyi, M.A. Postow, Checkpoint blocking antibodies in cancer immunotherapy. FEBS Lett. 588, 368-376 (2014). https ://doi.org/10.1016/j.febslet.2013.10.015

33. A. Markham, S. Duggan, Cemiplimab: first global approval. Drugs 78, 1841-1846 (2018). https://doi.org/10.1007/s4026 5-018-1012-5

34. E.S. Kim, Avelumab: first global approval. Drugs 77, 929937 (2017). https://doi.org/10.1007/s40265-017-0749-6

35. Y.Y. Syed, Durvalumab: first global approval. Drugs 77, 1369-1376 (2017). https://doi.org/10.1007/s4026 5-017-0782-5

36. M.A. Postow, J. Chesney, A.C. Pavlick, C. Robert, K. Grossmann et al., Nivolumab and ipilimumab versus ipilimumab in untreated melanoma. New Engl. J. Med. 372, 2006-2017 (2015). https://doi.org/10.1056/NEJMoa1414428

37. R. Sankaranarayanan, HPV vaccination: the most pragmatic cervical cancer primary prevention strategy. Int. J. Gynecol. Obstet. 131, S33-S35 (2015). https://doi.org/10.1016/j. ijgo.2015.02.014

38. I. Melero, G. Gaudemack, W. Gerritsen, C. Huber, G. Parmiani et al., Therapeutic vaccines for cancer: an overview of clinical trials. Nat. Rev. Clin. Oncol. 11, 509-524 (2014). https://doi.org/10.1038/nrclinonc.2014.111

39. J. Schlom, Therapeutic cancer vaccines: current status and moving forward. Jnci-J. Natl. Cancer I 104, 599-613 (2012). https://doi.org/10.1093/jnci/djs033

40. O.J. Finn, S.N. Khleif, R.B. Herberman, The FDA guidance on therapeutic cancer vaccines: the need for revision to include preventive cancer vaccines or for a new guidance dedicated to them. Cancer Prev. Res. 8, 1011-1016 (2015). https://doi.org/10.1158/1940-6207.CAPR-15-0234

41. D.J. Schwartzentruber, D.H. Lawson, J.M. Richards, R.M. Conry, D.M. Miller et al., Gp100 peptide vaccine and interleukin-2 in patients with advanced melanoma. New Engl. J. Med. 364, 2119-2127 (2011). https://doi.org/10.1056/ NEJMoa1012863

42. J.A. Sosman, C. Carrillo, W.J. Urba, L. Flaherty, M.B. Atkins et al., Three phase II cytokine working group trials of gp100 $(210 \mathrm{M})$ peptide plus high-dose interleukin-2 in patients with HLA-A2-positive advanced melanoma. J. Clin. Oncol. 26, 2292-2298 (2008). https://doi.org/10.1200/Jco.2007.13.3165

43. J. Karbach, A. Neumann, A. Atmaca, C. Wahle, K. Brand et al., Efficient in vivo priming by vaccination with recombinant NY-ESO-1 protein and CpG in antigen naive prostate 
cancer patients. Clin. Cancer Res. 17, 861-870 (2011). https ://doi.org/10.1158/1078-0432.CCR-10-1811

44. J. Schlom, Therapeutic cancer vaccines: current status and moving forward. J. Natl. Cancer I 104, 599-613 (2012). https ://doi.org/10.1093/jnci/djs033

45. M. Saxena, N. Bhardwaj, Turbocharging vaccines: emerging adjuvants for dendritic cell based therapeutic cancer vaccines. Curr. Opin. Immunol. 47, 35-43 (2017). https://doi. org/10.1016/j.coi.2017.06.003

46. M. Mueller, R. Amann, T. Feger, H.G. Rammensee, The mode of action of Orf virus: a novel viral vector for therapeutic cancer vaccines. Cancer Immunol. Res. 4, 2326-6074 (2016). https://doi.org/10.1158/2326-6074.Cricimteatiaacr 15-A170

47. Y. Fujiwara, K. Okada, T. Omori, K. Sugimura, H. Miyata et al., Multiple therapeutic peptide vaccines for patients with advanced gastric cancer. Int. J. Oncol. 50, 1655-1662 (2017). https://doi.org/10.3892/ijo.2017.3955

48. S. Mohammed, N. Bakshi, N. Chaudri, J. Akhter, M. Akhtar, Cancer vaccines: past, present, and future. Adv. Anat. Pathol. 23, 180-191 (2016). https://doi.org/10.1097/PAP.00000 00000000116

49. M.E. Dudley, S.A. Rosenberg, Adoptive cell transfer therapy. Semin. Oncol. 34, 524-531 (2007). https://doi.org/10.1053/j. seminoncol.2007.09.002

50. M.E. Dudley, S.A. Rosenberg, Adoptive-cell-transfer therapy for the treatment of patients with cancer. Nat. Rev. Cancer 3, 666-675 (2003). https://doi.org/10.1038/nrc1167

51. Z. Wang, Z. Wu, Y. Liu, W. Han, New development in CAR-T cell therapy. J. Hematol. Oncol. 10, 53 (2017). https://doi. org/10.1186/s13045-017-0423-1

52. M.M. D’Aloia, I.G. Zizzari, B. Sacchetti, L. Pierelli, M. Alimandi, CAR-T cells: the long and winding road to solid tumors. Cell Death Dis. 9, 282 (2018). https://doi. org/10.1038/s41419-018-0278-6

53. C.W. Shields, M.A. Evans, L.L.W. Wang, N. Baugh, S. Iyer et al., Cellular backpacks for macrophage immunotherapy. Sci. Adv. 6, 6579 (2020). https://doi.org/10.1126/sciad v.aaz6579

54. G. Dranoff, Cytokines in cancer pathogenesis and cancer therapy. Nat. Rev. Cancer 4, 11-22 (2004). https://doi. org/10.1038/nrc1252

55. A. Showalter, A. Limaye, J.L. Oyer, R. Igarashi, C. Kittipatarin, A.J. Copik, A.R. Khaled, Cytokines in immunogenic cell death: applications for cancer immunotherapy. Cytokine 97, 123-132 (2017). https://doi.org/10.1016/j.cyto.2017.05.024

56. P. Berraondo, M.F. Sanmamed, M.C. Ochoa, I. Etxeberria, M.A. Aznar et al., Cytokines in clinical cancer immunotherapy. Br. J. Cancer 120, 6-15 (2019). https://doi.org/10.1038/ s41416-018-0328-y

57. S. Lee, K. Margolin, Cytokines in cancer immunotherapy. Cancers 3, 3856-3893 (2011). https://doi.org/10.3390/cance rs 3043856

58. W. Liao, J.X. Lin, W.J. Leonard, IL-2 family cytokines: new insights into the complex roles of IL-2 as a broad regulator of T helper cell differentiation. Curr. Opin. Immunol. 23, 598-604 (2011). https://doi.org/10.1016/j.coi.2011.08.003

59. X. Wang, Y. Lin, Tumor necrosis factor and cancer, buddies or foes? Acta Pharmacol. Sin. 29, 1275-1288 (2008). https ://doi.org/10.1111/j.1745-7254.2008.00889.x

60. A. Ashkenazi, R.C. Pai, S. Fong, S. Leung, D.A. Lawrence et al., Safety and antitumor activity of recombinant soluble Apo2 ligand. J. Clin. Invest. 104, 155-162 (1999). https://doi. org/10.1172/JCI6926

61. A.E. Foster, K. Forrester, Y.C. Li, D.J. Gottlieb, Ex-vivo uses and applications of cytokines for adoptive immunotherapy in cancer. Curr. Pharm. Des. 10, 1207-1220 (2004). https://doi. org/10.2174/1381612043452631

62. Y. Fan, J.J. Moon, Nanoparticle drug Ddelivery systems designed to improve cancer vaccines and immunotherapy. Vaccines 3, 662-685 (2015). https://doi.org/10.3390/vacci nes 3030662

63. S.Y. Qin, Y.J. Cheng, Q. Lei, A.Q. Zhang, X.Z. Zhang, Combinational strategy for high-performance cancer chemotherapy. Biomaterials 171, 178-197 (2018). https://doi. org/10.1016/j.biomaterials.2018.04.027

64. M. Zhang, E.G. Liu, Y.N. Cui, Y.Z. Huang, Nanotechnologybased combination therapy for overcoming multidrug-resistant cancer. Cancer Biol. Med. 14, 212-227 (2017). https:// doi.org/10.20892/j.issn.2095-3941.2017.0054

65. W. Mu, D. Jiang, S. Mu, S. Liang, Y. Liu, N. Zhang, Promoting early diagnosis and precise therapy of hepatocellular carcinoma by glypican-3-targeted synergistic chemophotothermal theranostics. ACS Appl. Mater. Interfaces. 11, 23591-23604 (2019). https://doi.org/10.1021/acsami.9b055 26

66. C.C. Wang, L.C. Liu, H.L. Cao, W. Zhang, Intracellular GSHactivatable galactoside supramolecular photosensitizers for targeted photodynamic therapy and chemotherapy. J. Control. Release 259, E135-E136 (2017). https://doi.org/10.1016/j. jconrel.2017.03.276

67. Y. Suzuki, K. Kohno, K. Matsue, A. Sakakibara, E. Ishikawa et al., PD-L1 (SP142) expression in neoplastic cells predicts a poor prognosis for patients with intravascular large B-cell lymphoma treated with rituximab-based multi-agent chemotherapy. Cancer Med. (2020). https://doi.org/10.1002/ cam4.3104

68. M. Michaud, I. Martins, A.Q. Sukkurwala, S. Adjemian, Y. Ma et al., Autophagy-dependent anticancer immune responses induced by chemotherapeutic agents in mice. Science 334, 1573-1577 (2011). https://doi.org/10.1126/scien ce. 1208347

69. C.W. Tseng, C.F. Hung, R.D. Alvarez, C. Trimble, W.K. Huh et al., Pretreatment with cisplatin enhances E7-specific CD8 + T-Cell-mediated antitumor immunity induced by DNA vaccination. Clin. Cancer Res. 14, 3185-3192 (2008). https ://doi.org/10.1158/1078-0432.CCR-08-0037

70. K.N. Kodumudi, K. Woan, D.L. Gilvary, E. Sahakian, S. Wei, J.Y. Djeu, A novel chemoimmunomodulating property of docetaxel: suppression of myeloid-derived suppressor cells 
in tumor bearers. Clin. Cancer Res. 16, 4583-4594 (2010). https://doi.org/10.1158/1078-0432.CCR-10-0733

71. Y. Eralp, X. Wang, J.P. Wang, M.F. Maughan, J.M. Polo, L.B. Lachman, Doxorubicin and paclitaxel enhance the antitumor efficacy of vaccines directed against HER2/neu in a murine mammary carcinoma model. Breast Cancer Res. 6, R275R283 (2004). https://doi.org/10.1186/bcr787

72. T.J. Haggerty, I.S. Dunn, L.B. Rose, E.E. Newton, S. Martin, J.L. Riley, J.T. Kurnick, Topoisomerase inhibitors modulate expression of melanocytic antigens and enhance $\mathrm{T}$ cell recognition of tumor cells. Cancer Immunol. Immun. 60, 133-144 (2011). https://doi.org/10.1007/s0026 2-010-0926-X

73. J.W. Hodge, C.T. Garnett, B. Farsaci, C. Palena, K.Y. Tsang, S. Ferrone, S.R. Gameiro, Chemotherapy-induced immunogenic modulation of tumor cells enhances killing by cytotoxic T lymphocytes and is distinct from immunogenic cell death. Int. J. Cancer 133, 624-636 (2013). https://doi.org/10.1002/ ijc. 28070

74. H. Ghebeh, C. Lehe, E. Barhoush, K. Al-Romaih, A. Tulbah et al., Doxorubicin downregulates cell surface B7-H1 expression and upregulates its nuclear expression in breast cancer cells: role of B7-H1 as an anti-apoptotic molecule. Breast Cancer Res. 12, R48 (2010). https://doi.org/10.1186/bcr2605

75. W.J. Lesterhuis, C.J. Punt, S.V. Hato, D. Eleveld-Trancikova, B.J. Jansen et al., Platinum-based drugs disrupt STAT6mediated suppression of immune responses against cancer in humans and mice. J. Clin. Invest. 121, 3100-3108 (2011). https://doi.org/10.1172/JCI43656

76. T.J. Lynch, I. Bondarenko, A. Luft, P. Serwatowski, F. Barlesi et al., Ipilimumab in combination with paclitaxel and carboplatin as first-line treatment in stage IIIB/IV non-small-cell lung cancer: results from a randomized, double-blind, multicenter phase II study. J. Clin. Oncol. 30, 2046-2054 (2012). https://doi.org/10.1200/JCO.2011.38.4032

77. R. Ramakrishnan, D. Assudani, S. Nagaraj, T. Hunter, H.I. Cho, S. Antonia, S. Altiok, E. Celis, D.I. Gabrilovich, Chemotherapy enhances tumor cell susceptibility to CTL-mediated killing during cancer immunotherapy in mice. J. Clin. Invest. 120, 1111-1124 (2010). https://doi.org/10.1172/JCI40269

78. K. Oleinika, R.J. Nibbs, G.J. Graham, A.R. Fraser, Suppression, subversion and escape: the role of regulatory $\mathrm{T}$ cells in cancer progression. Clin. Exp. Immunol. 171, 36-45 (2013). https://doi.org/10.1111/j.1365-2249.2012.04657.x

79. A. Tanaka, S. Sakaguchi, Regulatory $\mathrm{T}$ cells in cancer immunotherapy. Cell Res. 27, 109-118 (2017). https://doi. org/10.1038/cr.2016.151

80. K. Shitara, H. Nishikawa, Regulatory T cells: a potential target in cancer immunotherapy. Ann. N. Y. Acad. Sci. 1417, 104-115 (2018). https://doi.org/10.1111/nyas.13625

81. V. Cerullo, I. Diaconu, L. Kangasniemi, M. Rajecki, S. Escutenaire et al., Immunological effects of low-dose cyclophosphamide in cancer patients treated with oncolytic adenovirus. Mol. Ther. 19, 1737-1746 (2011). https://doi. org/10.1038/mt.2011.113
82. E. Ellebaek, L. Engell-Noerregaard, T.Z. Iversen, T.M. Froesig, S. Munir, S.R. Hadrup, M.H. Andersen, I.M. Svane, Metastatic melanoma patients treated with dendritic cell vaccination, Interleukin-2 and metronomic cyclophosphamide: results from a phase II trial. Cancer Immunol. Immun. 61, 1791-1804 (2012). https://doi.org/10.1007/s0026 2-012-1242-4

83. A.K. Nowak, A.M. Cook, A.M. McDonnell, M.J. Millward, J. Creaney et al., A phase $1 \mathrm{~b}$ clinical trial of the CD40-activating antibody $\mathrm{CP}-870,893$ in combination with cisplatin and pemetrexed in malignant pleural mesothelioma. Ann. Oncol. 26, 2483-2490 (2015). https://doi.org/10.1093/ annonc/mdv387

84. L.E. Kandalaft, D.J. Powell Jr., C.L. Chiang, J. Tanyi et al., Autologous lysate-pulsed dendritic cell vaccination followed by adoptive transfer of vaccine-primed ex vivo co-stimulated $\mathrm{T}$ cells in recurrent ovarian cancer. Oncoimmunology 2, e22664 (2013). https://doi.org/10.4161/ onci.22664

85. M. Maio, A.M. Di Giacomo, C. Robert, A.M. Eggermont, Update on the role of ipilimumab in melanoma and first data on new combination therapies. Curr. Opin. Oncol. 25, 166172 (2013). https://doi.org/10.1097/CCO.0b013e32835dae4 $\mathrm{f}$

86. M.J. Smyth, S.F. Ngiow, A. Ribas, M.W. Teng, Combination cancer immunotherapies tailored to the tumour microenvironment. Nat. Rev. Clin. Oncol 13, 143-158 (2016). https://doi. org/10.1038/nrclinonc.2015.209

87. G. Middleton, P. Silcocks, T. Cox, J. Valle, J. Wadsley et al., Gemcitabine and capecitabine with or without telomerase peptide vaccine GV1001 in patients with locally advanced or metastatic pancreatic cancer (TeloVac): an open-label, randomised, phase 3 trial. Lancet Oncol. 15, 829-840 (2014). https://doi.org/10.1016/S1470-2045(14)70236-0

88. X. Zang, X. Zhao, H. Hu, M. Qiao, Y. Deng, D. Chen, Nanoparticles for tumor immunotherapy. Eur. J. Pharm. Biopharm. 115, 243-256 (2017). https://doi.org/10.1016/j. ejpb.2017.03.013

89. Q. Hu, W. Sun, C. Wang, Z. Gu, Recent advances of cocktail chemotherapy by combination drug delivery systems. Adv. Drug Deliv. Rev. 98, 19-34 (2016). https://doi.org/10.1016/j. addr.2015.10.022

90. D.B. Pacardo, F.S. Ligler, Z. Gu, Programmable nanomedicine: synergistic and sequential drug delivery systems. Nanoscale 7, 3381-3391 (2015). https://doi.org/10.1039/ c4nr07677j

91. R. Langer, N.A. Peppas, Advances in biomaterials, drug delivery, and bionanotechnology. AIChE J. 49, 2990-3006 (2003). https://doi.org/10.1002/aic.690491202

92. Z. Xie, Y. Su, G.B. Kim, E. Selvi, C. Ma, V. Aragon-Sanabria, J.T. Hsieh, C. Dong, J. Yang, Immune cell-mediated biodegradable theranostic nanoparticles for melanoma targeting and drug delivery. Small (2017). https://doi.org/10.1002/ smll.201603121

93. J.A. Kemp, M.S. Shim, C.Y. Heo, Y.J. Kwon, "Combo" nanomedicine: co-delivery of multi-modal therapeutics 
for efficient, targeted, and safe cancer therapy. Adv. Drug Deliv. Rev. 98, 3-18 (2016). https://doi.org/10.1016/j. addr.2015.10.019

94. R.X. Zhang, H.L. Wong, H.Y. Xue, J.Y. Eoh, X.Y. Wu, Nanomedicine of synergistic drug combinations for cancer therapy: strategies and perspectives. J. Control. Release 240, 489-503 (2016). https://doi.org/10.1016/j.jconrel.2016.06.012

95. R. Kuai, W.M. Yuan, S. Son, J. Nam, J. Xu, Y.C. Fan, A. Schwendeman, J.J. Moon, Elimination of established tumors with nanodisc-based combination chemoimmunotherapy. Sci. Adv. 4, eaao1736 (2018). https://doi.org/10.1126/sciad v.aao1736

96. M.B. Heo, S.Y. Kim, W.S. Yun, Y.T. Lim, Sequential delivery of an anticancer drug and combined immunomodulatory nanoparticles for efficient chemoimmunotherapy. Int. J. Nanomed. 10, 5981-5993 (2015). https://doi.org/10.2147/ Ijn.S90104

97. Y. Shao, B. Liu, Z. Di, G. Zhang, L.D. Sun, L. Li, C.H. Yan, Engineering of upconverted metal-organic frameworks for near-infrared light-triggered combinational photodynamic/chemo-/immunotherapy against hypoxic tumors. J. Am. Chem. Soc. 142(8), 3939-3946 (2020). https://doi. org/10.1021/jacs.9b12788

98. F. Zhou, B. Feng, H. Yu, D. Wang, T. Wang, Y. Ma, S. Wang, Y. Li, Tumor microenvironment-activatable prodrug vesicles for nanoenabled cancer chemoimmunotherapy combining immunogenic cell death induction and CD47 blockade. Adv. Mater. 31, e1805888 (2019). https://doi. org/10.1002/adma.201805888

99. T. Wang, J. Zhang, T. Hou, X. Yin, N. Zhang, Selective targeting of tumor cells and tumor associated macrophages separately by twin-like core-shell nanoparticles for enhanced tumor-localized chemoimmunotherapy. Nanoscale 11, 13934-13946 (2019). https://doi. org/10.1039/c9nr03374b

100. T.L. ten Hagen, A.L. Seynhaeve, S.T. van Tiel, D.J. Ruiter, A.M. Eggermont, Pegylated liposomal tumor necrosis factor-alpha results in reduced toxicity and synergistic antitumor activity after systemic administration in combination with liposomal doxorubicin (Doxil) in soft tissue sarcomabearing rats. Int. J. Cancer 97, 115-120 (2002). https://doi. org/10.1002/ijc. 1578

101. C.L. Guo, Y.A. Chen, W.J. Gao, A.T. Chang, Y.J. Ye et al., Liposomal nanoparticles carrying anti-IL6R antibody to the tumour microenvironment inhibit metastasis in two molecular subtypes of breast cancer mouse models. Theranostics 7, 775-788 (2017). https://doi.org/10.7150/thno.17237

102. J.J. Wei, Y. Long, R. Guo, X.L. Liu, X. Tang et al., Multifunctional polymeric micelle-based chemo-immunotherapy with immune checkpoint blockade for efficient treatment of orthotopic and metastatic breast cancer. Acta Pharm. Sin. B 9, 819-831 (2019). https://doi.org/10.1016/j.apsb.2019.01.018

103. B. Zhang, T. Wang, S. Yang, Y. Xiao, Y. Song, N. Zhang, S. Garg, Development and evaluation of oxaliplatin and irinotecan co-loaded liposomes for enhanced colorectal cancer therapy. J. Control. Release 238, 10-21 (2016). https ://doi.org/10.1016/j.jconrel.2016.07.022

104. Z. Gu, Q. Wang, Y. Shi, Y. Huang, J. Zhang, X. Zhang, G. Lin, Nanotechnology-mediated immunochemotherapy combined with docetaxel and PD-L1 antibody increase therapeutic effects and decrease systemic toxicity. J. Control. Release 286, 369-380 (2018). https://doi.org/10.1016/j. jconrel.2018.08.011

105. Y. Liu, X.G. Chen, P.P. Yang, Z.Y. Qiao, H. Wang, Tumor microenvironmental $\mathrm{pH}$ and enzyme dual responsive polymer-liposomes for synergistic treatment of cancer immunochemotherapy. Biomacromol 20, 882-892 (2019). https:// doi.org/10.1021/acs.biomac.8b01510

106. J.Q. Lu, X.S. Liu, Y.P. Liao, X. Wang, A. Ahmed, W. Jiang, Y. Ji, H. Meng, A.E. Nel, Breast cancer chemo-immunotherapy through liposomal delivery of an immunogenic cell death stimulus plus interference in the IDO-1 pathway. ACS Nano 12, 11041-11061 (2018). https://doi.org/10.1021/acsna no. 8 b05189

107. Z.W. Su, Z.C. Xiao, Y. Wang, J.S. Huang, Y.C. An, X. Wang, X.T. Shuai, Codelivery of anti-PD-1 antibody and paclitaxel with matrix metalloproteinase and $\mathrm{pH}$ dual-sensitive micelles for enhanced tumor chemoimmunotherapy. Small 16, 1906832 (2020). https://doi.org/10.1002/Smll.201906832

108. J. Hernandez-Gil, M. Cobaleda-Siles, A. Zabaleta, L. Salassa, J. Calvo, J.C. Mareque-Rivas, An iron oxide nanocarrier loaded with a Pt(IV) prodrug and immunostimulatory dsRNA for combining complementary cancer killing effects. Adv. Healthc. Mater. 4, 1034-1042 (2015). https:// doi.org/10.1002/adhm.201500080

109. I.H. Lee, S. An, M.K. Yu, H.K. Kwon, S.H. Im, S. Jon, Targeted chemoimmunotherapy using drug-loaded aptamerdendrimer bioconjugates. J. Control. Release 155, 435-441 (2011). https://doi.org/10.1016/j.jconrel.2011.05.025

110. C. Xia, S. Yin, S. Xu, G. Ran, M. Deng et al., Low molecular weight heparin-coated and dendrimer-based core-shell nanoplatform with enhanced immune activation and multiple antimetastatic effects for melanoma treatment. Theranostics $\mathbf{9}$, 337-354 (2019). https://doi.org/10.7150/thno.29026

111. S. Shen, H.J. Li, K.G. Chen, Y.C. Wang, X.Z. Yang, Z.X. Lian, J.Z. Du, J. Wang, Spatial targeting of tumor-associated macrophages and tumor cells with a $\mathrm{pH}$-sensitive cluster nanocarrier for cancer chemoimmunotherapy. Nano Lett. 17, 3822-3829 (2017). https://doi.org/10.1021/acs.nanol ett. $7 \mathrm{~b} 01193$

112. W. Ou, J.H. Byeon, R.K. Thapa, S.K. Ku, C.S. Yong, J.O. Kim, Plug-and-play nanorization of coarse black phosphorus for targeted chemo-photoimmunotherapy of colorectal cancer. ACS Nano 12, 10061-10074 (2018). https://doi.org/10.1021/ acsnano. 8 b04658

113. L. Chen, L.L. Zhou, C.H. Wang, Y. Han, Y.L. Lu et al., Tumor-targeted drug and $\mathrm{CpG}$ delivery system for phototherapy and docetaxel-enhanced immunotherapy with polarization toward M1-type macrophages on triple negative breast cancers. Adv. Mater. 31, 1904997 (2019). https://doi. org/10.1002/Adma.201904997 
114. X. Wu, Y. Wu, H. Ye, S. Yu, C. He, X. Chen, Interleukin-15 and cisplatin co-encapsulated thermosensitive polypeptide hydrogels for combined immuno-chemotherapy. J. Control. Release 255, 81-93 (2017). https://doi.org/10.1016/j.jconr el.2017.04.011

115. X. Dong, A. Yang, Y. Bai, D. Kong, F. Lv, Dual fluorescence imaging-guided programmed delivery of doxorubicin and $\mathrm{CpG}$ nanoparticles to modulate tumor microenvironment for effective chemo-immunotherapy. Biomaterials 230, 119659 (2020). https://doi.org/10.1016/j.biomaterials.2019.119659

116. P. Kadiyala, D. Li, F.M. Nunez, D. Altshuler, R. Doherty et al., High-density lipoprotein-mimicking nanodiscs for chemo-immunotherapy against glioblastoma multiforme. ACS Nano 13, 1365-1384 (2019). https://doi.org/10.1021/ acsnano.8b06842

117. M. Wu, X. Liu, H. Bai, L. Lai, Q. Chen, G. Huang, B. Liu, G. Tang, Surface-layer protein-enhanced immunotherapy based on cell membrane-coated nanoparticles for the effective inhibition of tumor growth and metastasis. ACS Appl. Mater. Interfaces. 11, 9850-9859 (2019). https://doi. org/10.1021/acsami.9b00294

118. Q. Song, Y. Yin, L. Shang, T. Wu, D. Zhang et al., Tumor microenvironment responsive nanogel for the combinatorial antitumor effect of chemotherapy and immunotherapy. Nano Lett. 17, 6366-6375 (2017). https://doi.org/10.1021/ acs.nanolett.7b03186

119. B.S. Pattni, V.V. Chupin, V.P. Torchilin, New developments in liposomal drug delivery. Chem. Rev. 115, 10938-10966 (2015). https://doi.org/10.1021/acs.chemrev.5b00046

120. R.K. O’Reilly, C.J. Hawker, K.L. Wooley, Cross-linked block copolymer micelles: functional nanostructures of great potential and versatility. Chem. Soc. Rev. 35, 10681083 (2006). https://doi.org/10.1039/b514858h

121. K. Kataoka, A. Harada, Y. Nagasaki, Block copolymer micelles for drug delivery: design, characterization and biological significance. Adv. Drug Deliv. Rev. 47, 113-131 (2001). https://doi.org/10.1016/s0169-409x(00)00124-1

122. H.K. Makadia, S.J. Siegel, Poly lactic-co-glycolic acid (PLGA) as biodegradable controlled drug delivery carrier. Polymers 3, 1377-1397 (2011). https://doi.org/10.3390/ polym 3031377

123. R. Gref, Y. Minamitake, M.T. Peracchia, V. Trubetskoy, V. Torchilin, R. Langer, Biodegradable long-circulating polymeric nanospheres. Science 263, 1600-1603 (1994). https ://doi.org/10.1126/science.8128245

124. Y.K. Luu, K. Kim, B.S. Hsiao, B. Chu, M. Hadjiargyrou, Development of a nanostructured DNA delivery scaffold via electrospinning of PLGA and PLA-PEG block copolymers. J. Control. Release 89, 341-353 (2003). https://doi. org/10.1016/s0168-3659(03)00097-X

125. J. Zimmermann, N. Jurgensen, A.J. Morfa, B.H. Wang, S. Tekoglu, G. Hernandez-Sosa, Poly(lactic-co-glycolic acid) (PLGA) as ion-conducting polymer for biodegradable lightemitting electrochemical cells. ACS Sustain. Chem. Eng. 4, 7050-7055 (2016). https://doi.org/10.1021/acssuschem eng.6b01953
126. N. Rapoport, Physical stimuli-responsive polymeric micelles for anti-cancer drug delivery. Prog. Polym. Sci. 32, 962-990 (2007). https://doi.org/10.1016/j.progpolyms ci.2007.05.009

127. T.Y. Kim, D.W. Kim, J.Y. Chung, S.G. Shin, S.C. Kim et al., Phase I and pharmacokinetic study of Genexol-PM, a cremophor-free, polymeric micelle-formulated paclitaxel, in patients with advanced malignancies. Clin. Cancer Res. 10, 3708-3716 (2004). https://doi.org/10.1158/1078-0432. Ccr-03-0655

128. X.J. Chen, X.Q. Zhang, M.X. Tang, Q. Liu, G. Zhou, Anti-PD-L1-modified and ATRA-loaded nanoparticles for immuno-treatment of oral dysplasia and oral squamous cell carcinoma. Nanomedicine 15, 951-968 (2020). https://doi. org/10.2217/nnm-2019-0397

129. L.L. Dai, X. Li, M.J. Yao, P.Y. Niu, X.C. Yuan et al., Programmable prodrug micelle with size-shrinkage and chargereversal for chemotherapy-improved IDO immunotherapy. Biomaterials 241, 119901 (2020). https://doi.org/10.1016/j. biomaterials.2020.119901

130. E. Perez-Herrero, A. Fernandez-Medarde, Advanced targeted therapies in cancer: drug nanocarriers, the future of chemotherapy. Eur. J. Pharm. Biopharm. 93, 52-79 (2015). https:// doi.org/10.1016/j.ejpb.2015.03.018

131. H.J. Hsu, J. Bugno, S.R. Lee, S. Hong, Dendrimer-based nanocarriers: a versatile platform for drug delivery. Wires Nanomed. Nanobi. 9, e1409 (2017). https://doi.org/10.1002/ Wnan.1409

132. H.J. Li, J.Z. Du, X.J. Du, C.F. Xu, C.Y. Sun et al., Stimuliresponsive clustered nanoparticles for improved tumor penetration and therapeutic efficacy. Proc. Natl. Acad. Sci. U.S.A. 113, 4164-4169 (2016). https://doi.org/10.1073/pnas.15220 80113

133. J.P. Yang, Q. Zhang, H. Chang, Y.Y. Cheng, Surface-engineered dendrimers in gene delivery. Chem. Rev. 115, 52745300 (2015). https://doi.org/10.1021/cr500542t

134. T.A. Gilewski, G. Ragupathi, M. Dickler, S. Powell, S. Bhuta et al., Immunization of high-risk breast cancer patients with clustered sTn-KLH conjugate plus the immunologic adjuvant QS-21. Clin. Cancer Res. 13, 2977-2985 (2007). https://doi. org/10.1158/1078-0432.CCR-06-2189

135. S.F. Slovin, G. Ragupathi, C. Musselli, K. Olkiewicz, D. Verbel et al., Fully synthetic carbohydrate-based vaccines in biochemically relapsed prostate cancer: clinical trial results with alpha-N-acetylgalactosamine-O-serine/threonine conjugate vaccine. J. Clin. Oncol. 21, 4292-4298 (2003). https:// doi.org/10.1200/Jco.2003.04.112

136. L.M. Krug, G. Ragupathi, C. Hood, M.G. Kris, V.A. Miller et al., Vaccination of patients with small-cell lung cancer with synthetic fucosyl GM-1 conjugated to keyhole limpet hemocyanin. Clin. Cancer Res. 10, 6094-6100 (2004). https://doi. org/10.1158/1078-0432.Ccr-04-0482

137. T. Lang, Y. Liu, Z. Zheng, W. Ran, Y. Zhai, Q. Yin, P. Zhang, Y. Li, Cocktail strategy based on spatio-temporally controlled nano device improves therapy of breast cancer. Adv. Mater. 
31, e1903844 (2019). https://doi.org/10.1002/adma.20190 3844

138. H.J. Li, J.Z. Du, J. Liu, X.J. Du, S. Shen et al., Smart superstructures with ultrahigh $\mathrm{pH}$-sensitivity for targeting acidic tumor microenvironment: instantaneous size switching and improved tumor penetration. ACS Nano 10, 6753-6761 (2016). https://doi.org/10.1021/acsnano.6b02326

139. T. Jiang, W. Sun, Q. Zhu, N.A. Burns, S.A. Khan, R. Mo, Z. Gu, Furin-mediated sequential delivery of anticancer cytokine and small-molecule drug shuttled by graphene. Adv. Mater. 27, 1021-1028 (2015). https://doi.org/10.1002/ adma.201404498

140. X.X. Hu, Y. Wang, B. Peng, Chitosan-capped mesoporous silica nanoparticles as $\mathrm{pH}$-responsive nanocarriers for controlled drug release. Chem. Asian J. 9, 319-327 (2014). https ://doi.org/10.1002/asia.201301105

141. I.I. Slowing, J.L. Vivero-Escoto, C.W. Wu, V.S.Y. Lin, Mesoporous silica nanoparticles as controlled release drug delivery and gene transfection carriers. Adv. Drug Deliv. Rev. 60, 1278-1288 (2008). https://doi.org/10.1016/j. addr.2008.03.012

142. Q.S. Zheng, T.R. Lin, H.Y. Wu, L.Q. Guo, P.R. Ye et al., Mussel-inspired polydopamine coated mesoporous silica nanoparticles as $\mathrm{pH}$-sensitive nanocarriers for controlled release. Int. J. Pharmaceut. 463, 22-26 (2014). https://doi. org/10.1016/j.ijpharm.2013.12.045

143. D.W. Zheng, J.L. Chen, J.Y. Zhu, L. Rong, B. Li et al., Highly integrated nano-platform for breaking the barrier between chemotherapy and immunotherapy. Nano Lett. 16, 43414347 (2016). https://doi.org/10.1021/acs.nanolett.6b01432

144. D. Bobo, K.J. Robinson, J. Islam, K.J. Thurecht, S.R. Corrie, Nanoparticle-based medicines: a review of FDA-approved materials and clinical trials to date. Pharm. Res. 33, 23732387 (2016). https://doi.org/10.1007/s11095-016-1958-5

145. X. Liang, X. Ye, C. Wang, C. Xing, Q. Miao et al., Photothermal cancer immunotherapy by erythrocyte membrane-coated black phosphorus formulation. J. Control. Release 296, 150 161 (2019). https://doi.org/10.1016/j.jconrel.2019.01.027

146. J. Shao, H. Xie, H. Huang, Z. Li, Z. Sun et al., Biodegradable black phosphorus-based nanospheres for in vivo photothermal cancer therapy. Nat. Commun. 7, 12967 (2016). https:// doi.org/10.1038/ncomms 12967

147. W. Chen, J. Ouyang, H. Liu, M. Chen, K. Zeng et al., Black phosphorus nanosheet-based drug delivery system for synergistic photodynamic/photothermal/chemotherapy of cancer. Adv. Mater. 29, 1603864 (2017). https://doi.org/10.1002/ adma.201603864

148. M. Nishikawa, Y. Mizuno, K. Mohri, N. Matsuoka, S. Rattanakiat, Y. Takahashi, H. Funabashi, D. Luo, Y. Takakura, Biodegradable CpG DNA hydrogels for sustained delivery of doxorubicin and immunostimulatory signals in tumorbearing mice. Biomaterials 32, 488-494 (2011). https://doi. org/10.1016/j.biomaterials.2010.09.013

149. Y.K. Li, M. Fang, J. Zhang, J. Wang, Y. Song et al., Hydrogel dual delivered celecoxib and anti-PD-1 synergistically improve antitumor immunity. Oncoimmunology 5, 1074374 (2016). https://doi.org/10.1080/2162402X.2015.1074374

150. H. Qiao, X. Chen, E. Chen, J. Zhang, D. Huang et al., Folated $\mathrm{pH}$-degradable nanogels for the simultaneous delivery of docetaxel and an IDO1-inhibitor in enhancing cancer chemoimmunotherapy. Biomater. Sci. 7, 2749-2758 (2019). https ://doi.org/10.1039/c9bm00324j

151. Q. Lv, C.L. He, F.L. Quan, S.J. Yu, X.S. Chen, DOX/IL-2/ IFN-gamma co-loaded thermo-sensitive polypeptide hydrogel for efficient melanoma treatment. Bioact. Mater. 3, 118-128 (2018). https://doi.org/10.1016/j.bioactmat.2017.08.003

152. H. Jin, C. Wan, Z. Zou, G. Zhao, L. Zhang et al., Tumor ablation and therapeutic immunity induction by an injectable peptide hydrogel. ACS Nano 12, 3295-3310 (2018). https:// doi.org/10.1021/acsnano.7b08148

153. P.F. Zhao, Y.H. Wang, X.J. Kang, A.H. Wu, W.M. Yin et al., Dual-targeting biomimetic delivery for anti-glioma activity via remodeling the tumor microenvironment and directing macrophagemediated immunotherapy. Chem. Sci. 9, 26742689 (2018). https://doi.org/10.1039/c7sc04853j

154. H. Wang, Y. Tang, Y. Fang, M. Zhang, H. Wang, Z. He, B. Wang, Q. Xu, Y. Huang, Reprogramming tumor immune microenvironment (TIME) and metabolism via biomimetic targeting codelivery of shikonin/JQ1. Nano Lett. 19, 29352944 (2019). https://doi.org/10.1021/acs.nanolett.9b00021

155. V. Vijayan, S. Uthaman, I.K. Park, Cell membrane-camouflaged nanoparticles: a promising biomimetic strategy for cancer theragnostics. Polymers 10, 1009098 (2018). https:// doi.org/10.3390/polym10090983

156. H. Wang, Y. Liu, R. He, D. Xu, J. Zang, N. Weeranoppanant, H. Dong, Y. Li, Cell membrane biomimetic nanoparticles for inflammation and cancer targeting in drug delivery. Biomater. Sci. 8, 552-568 (2020). https://doi.org/10.1039/c9bm01392j

157. D. Dehaini, R.H. Fang, L. Zhang, Biomimetic strategies for targeted nanoparticle delivery. Bioeng. Transl. Med. 1, 30-46 (2016). https://doi.org/10.1002/btm2.10004

158. R.H. Fang, A.V. Kroll, W. Gao, L. Zhang, Cell membrane coating nanotechnology. Adv. Mater. 30, e1706759 (2018). https://doi.org/10.1002/adma.201706759

159. Y. Liu, J. Luo, X. Chen, W. Liu, T. Chen, Cell membrane coating technology: a promising strategy for biomedical applications. Nano-Micro Lett. 11, 100 (2019). https://doi. org/10.1007/s40820-019-0330-9

160. W. Du, C. Chen, P. Sun, S. Zhang, J. Zhang et al., Eliciting an immune hot tumor niche with biomimetic drug-based multi-functional nanohybrids augments immune checkpoint blockade-based breast cancer therapy. Nanoscale 12, 33173329 (2020). https://doi.org/10.1039/c9nr09835f

161. E. Lasalvia-Prisco, P. Goldschmidt, F. Galmarini, S. Cucchi, J. Vazquez et al., Addition of an induction regimen of antiangiogenesis and antitumor immunity to standard chemotherapy improves survival in advanced malignancies. Med. Oncol. 29, 3626-3633 (2012). https://doi.org/10.1007/s1203 2-012-0301-1

162. I. Liikanen, L. Ahtiainen, M.L. Hirvinen, S. Bramante, V. Cerullo et al., Oncolytic adenovirus with temozolomide 
induces autophagy and antitumor immune responses in cancer patients. Mol. Ther. 21, 1212-1223 (2013). https://doi. org/10.1038/mt.2013.51

163. B. Ding, X. Wu, W. Fan, Z. Wu, J. Gao et al., Anti-DR5 monoclonal antibody-mediated DTIC-loaded nanoparticles combining chemotherapy and immunotherapy for malignant melanoma: target formulation development and in vitro anticancer activity. Int. J. Nanomed. 6, 1991-2005 (2011). https ://doi.org/10.2147/IJN.S24094
164. B.Y. Ding, W. Zhang, X. Wu, J. Wang, C. Xie et al., DR5 mAb-conjugated, DTIC-loaded immuno-nanoparticles effectively and specifically kill malignant melanoma cells in vivo. Oncotarget 7, 57160-57170 (2016). https://doi.org/10.18632 /oncotarget.11014 